Distribution Categories:

Magnetic Fusion Energy (Uc-20)

MFE-Magnet1c Systems (UC-20b)

MFE-Fusion Systems (UC-20d)

ANL/FPP/TL- -183

DE85 004825

AKGONNE NATIONAL LABORATORY

9700 South Cass Avenue

Argonne, Illinois 60439

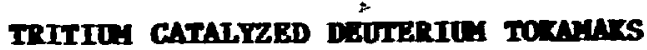

by

Ehud Greenspan* and George H. Miley

Fusion Studies Laboratory

Untversity of Illinois

Urbana, Illinols 61801

J. Jung and J. Gilligan**

Fusion Power Program

Argonne NatIonal Laboratory

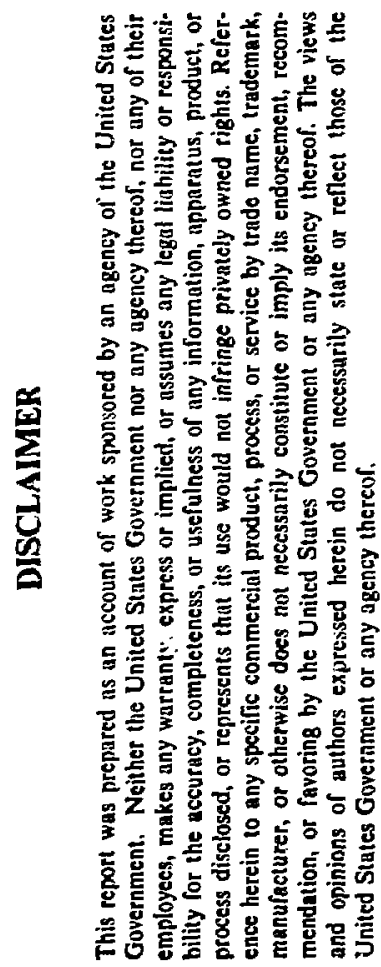

Apr11 1984

*Permanent address: Physics Department, Nuclear Research Center-Negev,

P. O. Box 9001 , Beer-Sheva 84190, Israel.

**Faculty Research Participant, Sumer 1983, on leave from the Fusion Studies

Laboratory, Untversity of Illinols. Present address: Department of Nuclear Engineering, North Carolina State University, P. 0. Box 7909, Raleigh, North Carolina 27695. 
ABSTRACT AND SUMMARY $\ldots \ldots \ldots \ldots \ldots \ldots \ldots \ldots \ldots \ldots \ldots \ldots \ldots \ldots \ldots \ldots \ldots \ldots \ldots$

1. InTRODUCTION $\ldots \ldots \ldots \ldots \ldots \ldots \ldots \ldots \ldots \ldots \ldots \ldots \ldots \ldots \ldots \ldots \ldots \ldots \ldots \ldots \ldots$

1.1 The TCD Fuel Cycle $\ldots \ldots \ldots \ldots \ldots \ldots \ldots \ldots \ldots \ldots \ldots \ldots \ldots \ldots \ldots \ldots$

1.2 D-D Based Reactor Studies - Review .................... 6

1.3 Objectlves, Scope, and Approach ..................... T

2. BLANKET STUDY $\ldots \ldots \ldots \ldots \ldots \ldots \ldots \ldots \ldots \ldots \ldots \ldots \ldots \ldots \ldots \ldots \ldots \ldots \ldots \ldots \ldots \ldots$

2.1 Study Goals and Strategy ........................... 9

2.2 Tritium Breeding Requirements ...................... 11

$2.33^{3}$ Inventory Requirements $\ldots \ldots \ldots \ldots \ldots \ldots \ldots \ldots \ldots \ldots \ldots \ldots \ldots \ldots$

2.4 Blanket Energy Multiplication $\ldots \ldots \ldots \ldots \ldots \ldots \ldots \ldots \ldots \ldots \ldots \ldots \ldots 20$

2.5 Illustrative TCD Blanket Characteribtics ................ 21

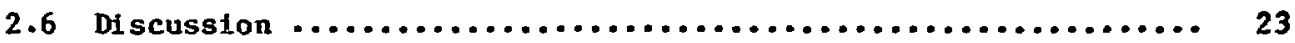

3. REACTOR DESIGN $\ldots \ldots \ldots \ldots \ldots \ldots \ldots \ldots \ldots \ldots \ldots \ldots \ldots \ldots \ldots \ldots \ldots \ldots \ldots \ldots \ldots \ldots$

3.1 St rategy and Assunptions . .......................... 23

3.2 Reference Reactors and Effects of Impurities ............. 27

3.3 Effect of Partial Burn of ${ }^{3}$ He $\ldots \ldots \ldots \ldots \ldots \ldots \ldots \ldots \ldots \ldots \ldots \ldots . \ldots \ldots$

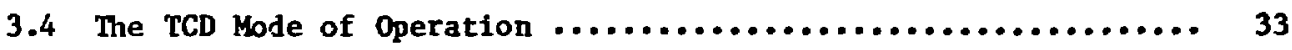

3.5 The Tritiun-Assisted TCD Kode of Operation ............... 36

3.6 Sensitivity Analysis ............................. 39

3.6 .1 Introduction ............................... 39

3.6.2 Effect of Blanket/Shield Thickness ................ 39

3.6.3 Effect of Blanket Energy Multiplication ............ 40

3.6.4 Effect of First Wa11 Thermal Loading ............... 41

4. POTENTIAL FOR IMPROVEMENTS $\ldots \ldots \ldots \ldots \ldots \ldots \ldots \ldots \ldots \ldots \ldots \ldots \ldots \ldots \ldots \ldots \ldots . \ldots 2$

4.1 Increased Blanket Energy Hultiplication .................. 42

4.2 Low Cost Shleld ..................................... 44

4.3 High Energy Conversion Efficlency ..................... 45

4.4 Discussion $\ldots \ldots \ldots \ldots \ldots \ldots \ldots \ldots \ldots \ldots \ldots \ldots \ldots \ldots \ldots \ldots \ldots \ldots \ldots \ldots \ldots$ 
raws or commis (Contd.)

Page

5. CONCLUDING REMARKS ................................. 45

ACKNOWLEDGMENTS $\ldots \ldots \ldots \ldots \ldots \ldots \ldots \ldots \ldots \ldots \ldots \ldots \ldots \ldots \ldots \ldots \ldots \ldots \ldots \ldots \ldots \ldots$

REFERENCES 


\section{LIST OF FIGURS}

No.

Title

Page

1 Schematics of $D-D$ based fusion fuel cycles. .....................

2 Effect of $\mathrm{PCA}$ and $\mathrm{H}_{2} \mathrm{O}$ volume fraction on the tritium breedfing per $D-T$ neutron. ${ }^{3}$ He volume fraction is $10 \%, \ldots \ldots \ldots \ldots \ldots \ldots \ldots \ldots \ldots$

3 Ef fect of $\mathrm{PCA}$ and $\mathrm{H}_{2} \mathrm{O}$ volume fraction on the tritivin breeding per D-D neutron. $3_{\mathrm{He}}$ volume fraction is $10 \mathrm{z} . \ldots \ldots \ldots \ldots \ldots \ldots \ldots \ldots \ldots$

4 Effect of ${ }^{3} \mathrm{He}$ volune fraction on the tritiun breeding per D-T neutron. PCA volue fraction is $10 \%$. ........................ 13

5 Effect of ${ }^{3} \mathrm{He}$ volume fraction on the tritlum breeding per D-D neutron. PCA volune fraction is $10 z . \ldots \ldots \ldots \ldots \ldots \ldots \ldots \ldots \ldots \ldots \ldots$

$6{ }^{3}$ He requirements for attaining a given tritium breeding ratio per D-T neutron. ...........................................

$7 \quad{ }^{3}$ Ke requirements for attainfing a given tritium breeding ratio per D-D neutron.

8 Effect of ${ }^{3} \mathrm{He}-t o-P C A$ volume ratio on the energy multiplication of $D-T\left(\epsilon_{D-T}\right)$ and $D-D\left(\epsilon_{D-D}\right)$ neutrons for $P C A: \mathrm{H}_{2} 0:{ }^{3} \mathrm{He}$ blazkets. .....

9 Effect of tritiun breeding ratio on the energy multiplication $(E)$

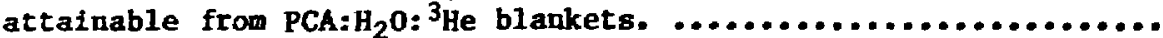

10 Ef fect of the fraction of ${ }^{3} \mathrm{He}$ escaping fustion $(\alpha)$ on the denteron density $\left(n_{D}\right)$, wajor radius $(R)$ and waximal wagnetic fleld strength $\left(B_{\max }\right)$ of $\mathrm{TBR}=0.4$ tokanaks. . ...........................

11 Effect of the fraction of ${ }^{3} \mathrm{He}$ escaping fusion $(\alpha)$ on the D-T neutron first wall loading $\left(\mathrm{r}_{\mathrm{D}-\mathrm{T}}\right)$ and fusion power density of TBR = 0.4 tokanaks.

12 Effect of the fraction of ${ }^{3}$ He escaping fusion $(\alpha)$ on the total capital cost (TCC) and cost of electricity (COE) of TBR $=0.4$

tokanaks.

13 Selected charcteristics of TCD tokanaks, Including major radius (R); maxinal magnetic field for $\bar{B}=10 \%$ ( $B_{\text {max }}$ ); fraction of ${ }^{3} \mathrm{He}$ escaping fusion ( $\alpha$ ); tritiu breeding ratio (TBR); cost of electricity $(\mathrm{COE})$; deuterons density $\left(\mathrm{n}_{\mathrm{D}}\right)$; confinenent paraneter (nT); $D-T$ neutrons first wall loading $3 \mathrm{r}_{\mathrm{D}-\mathrm{T}}$ ); ratio of $\mathrm{D}-\mathrm{T}$ to $\mathrm{D}-\mathrm{D}$ neutrons $\left(D-T / D-D_{n}\right)$; and average electron temperature $\left(\bar{T}_{e}\right) \cdot{ }^{3} \mathrm{He}$ recycling coeffleient $R_{3}=0.99 . \ldots \ldots \ldots \ldots \ldots \ldots \ldots \ldots \ldots \ldots \ldots \ldots$ 


\section{LIST Or HGULSs (Contd.)}

No.

Itrle

Page

14 Selected characteristics of TCD cokamaks, including major radius $(R)$; maxinal magnetic fleld for $B=107$ ( $B_{\max }$ ); fraction of ${ }^{3} \mathrm{He}$ escaplag fusion ( $\alpha$ ); tritiu breeding ratlo (TBR); cost of electricity (COE); deuterons density $\left(n_{D}\right)$; confinement parameter $(n \tau)$; ratio of $D-T$ to $D-D$ neutrons $\left(D-T / D-D_{n}\right)$; and average electron temperature $\left(\bar{T}_{e}\right)$. ${ }^{3} \mathrm{He}$ recycling coefficlent $\left.R_{3}=0.95\right) . \ldots \ldots . . .34$

15 Selected characteristics of TCD toksnaks, Including najor radius $(R)$; maxinal magnetic field for $B=10 \%$ ( $\left.B_{\text {max }}\right)$; fraction of ${ }^{3} \mathrm{He}$ escaping fuston (a); tritiun breeding ratio (TBR); cost of electriclty (COE); deuterons density ( $\left.n_{d}\right)$; confinenent parameter (uT); $D-T$ neutrons first wall loading $\left(\Gamma_{D-T}\right)$; ratio of $D-T$ to $D-D$ neutrons $D-T / D-D_{n} ;$ and average electron tenperature $\left(\bar{T}_{e}\right)$.

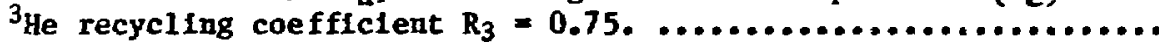

16 Effect of fraction of ${ }^{3} \mathrm{He}$ escaping fusion on the major radium (R); maximual magnetlc field for $\bar{B}=10 \pi\left(B_{\text {max }}\right.$ ); tritium breeding ratio (TBR), average plasna electron temperature $\left(\bar{T}_{e}\right)$; and cost of electricity (COE) of TCD tokanak reactors with nt of $2.4 \times 10^{21}$ or

$3.0 \times 10^{21} \mathrm{~m}^{-3} \mathrm{~s} . \ldots \ldots \ldots \ldots \ldots \ldots \ldots \ldots \ldots \ldots \ldots \ldots \ldots \ldots \ldots \ldots \ldots \ldots \ldots$

17 Comparison of cost of electricity (COE) of TCD, Cat-D, D-T, and $T B R=0.4$ tokanaks. $\ldots \ldots \ldots \ldots \ldots \ldots \ldots \ldots \ldots \ldots \ldots \ldots \ldots \ldots \ldots \ldots \ldots \ldots \ldots \ldots$ 


\section{LIST or TARES}

No.

Title

Page

1 Neutron and Energy Balance of Prine Ideal Fusion Fuel Cycles ...... 6

2 Tritium Breeding Requirements for TCD Blankets as a Function of $e=Y_{D-T} / Y_{D-D}$

3 Tritiun Breeding Ratio and Energy Multiplication of PCA: $\mathrm{H}_{2} 0:{ }^{3} \mathrm{Be}$

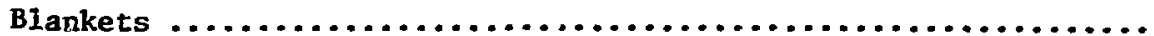

4 Breakdown of Energy Deposition 2n PCA: $\mathrm{H}_{2} \mathrm{O}:{ }^{3} \mathrm{He}$ Blankets Driven by D-T Neutrons

5 Breakdown of Energy Deposicion in PCA: $\mathrm{H}_{2} \mathrm{O}:{ }^{3} \mathrm{He}$ Blankets Driven by

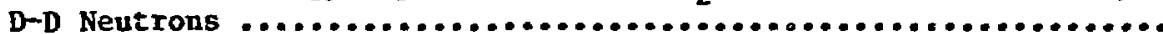

$6{ }^{3}$ He Inventory Requirements for, and Selected Characteristics of PCA: $\mathrm{H}_{2} \mathrm{O}:{ }^{3}$ He Blankets for TCD kode of Operation .................

7 A Summary of Assumptions Ised for TRAC-II Calculations

8 Selected Design and Performance Paraneters of the Reference D-T, Cat-D-T, and Cat-D Tokamaks .................................

9 Selected Design and Perfornance Paraneters of the Reference D-T,

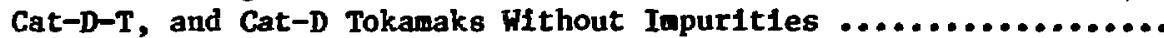

10 Selected Design and Performance Paraneters of Representative TCD Reactors - No Inpurities ....................................

11 Effect of Inboard Blanket/Shield Thickness $\left(\Delta_{B S}^{1}\right)$ on Selected Reactor Characteristics .......................................

12 Effect of Blanket Energy Multiplication for 14-MeV Neutrons $\left(\varepsilon_{D-T}\right)$ on selected Characteristics of the Cat-D and TCD Reactors .........

13 Effect of First Wall Thernal Loading ( $\phi_{w}$ ) Constraint on Selected Characteristics of the D-T and Cat-D Reactors

14 Effect of a Berylliu-Manganese Blanket on Selected Characteris-

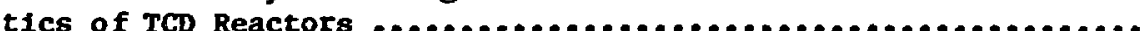

15 Sumary of Potential Inprovenents in the Cost of Electricity (COE) of TCD Versus D-T and Cat-D Reactors .......................... 


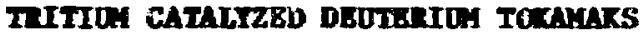

Ehud Greenspan and George H. Miley

J. Jung and J. Gilligan

\section{ABsmact Ald SUMART}

A prelizinary assessment of the promise of the Tritium Catalyzed Deuterium (TCD) tokamak power reactors relative to that of deuterfun-tritfum (D-T) and catalyzed deuterfum (Cat-D) tokamaks is undertaken. The TCD node of operation is arrived at by converting the ${ }^{3}$ He from the $D(D, n)^{3}$ He reaction into tritium, by neutron captare in the blanket; the tritfum thus produced is fed Into the plasma. There are three maln parts to the assessment: blanket study, reactor design and econonic analysis and an assessment of the prospects for Improvesients in the performance of TCD reactors (and in the promise of the TCD mode of operation, in general).

The blanket study is aimed at Identifying the minimum ${ }^{3}$ He Inventory required for converting ${ }^{3}$ He Into tritium at the rate of ${ }^{3}$ He production, and the maximum energy multiplication attainable. We consider only wLIDCAT-type blankets consisting of $\mathrm{PCA}$ and $\mathrm{H}_{2} \mathrm{O}$, to which ${ }^{3} \mathrm{He}$ is added. It is found that $P C A: H_{2} 0:{ }^{3} \mathrm{He}$ blankets can be designed for $\mathrm{TCD}$ reactors with modest ${ }^{3}$ He inventory -- of the order of $10 \mathrm{~kg}{ }^{3} \mathrm{He}$ per GW(e). Such an Inventory can be purchased for about $10 \mathrm{MS}$, $1 . e .$, without a significant econonic penalty. The use of beryllium as a neutron multipller is expected to lower the ${ }^{3}$ He Inventory requirements (as well as to increase the blanket energy aultiplfcation attainable).

Not having to Incorporate 1fthiun In the blanket and to produce at least one triton (net) per fusion neutron (as do blankets for D-T reactors), TCD blankets can be designed to be simpler, safer, easier to aaintain, and to operate at higher temperatures (and therefore, efficiencles) than D-? blankets. Woreover, it night be possible to design the first wall and hianket of TCD (as well as Cat-D) reactors to have a longer Iife than of $D-T$ reactors. Relative to the Cat-D node of operation, the TCD mode of operation relieves difficulties associated with the need to recirculate the ${ }^{3} \mathrm{He}$. 
The TCD reactor design and economic analysis is carried out using the methodology and ground rules developed at Argonne National Laboratory (ANL), as embodied in the computer code TRAC-II. All the reactors are designed to have $4000 \mathrm{MW}$ of nuclear power, are constrained by a first wall thermal loading of $1 \mathrm{MW} / \mathrm{m}^{2}$, and are assumed to have a plasma beta of $10 \%$. It is found that the conversion of ${ }^{3} \mathrm{He}$ into tritium enables a reduction in the reactor size but calls for an increase in the $n$ t confinement requirements as well as in the plasma density. As long as ignition can be achieved, the lower the fraction of the ${ }^{3} \mathrm{He}$ atoms escaping fusion, the better is the economics of the reactor. The cost of electricity (COE) of the TCD reactor is found to be approximately half-way in between the COEs of the reference STARFIRE $D-T$ and the WILDCAT Cat-D reactors. Further, a very preliminary examfnation of potential improvements in the performance of TCD reactors indicates that by optimizing the blanket design to have a higher energy multiplication, by minfmizing the shield cost, and by capitalizing on the high temperature operation ability of TCD blankets, it might be possible to arrive at TCD tokamak the COE from which approaches the $\mathrm{COE}$ from $\mathrm{D}-\mathrm{T}$ tokamaks.

Ignition of the low ${ }^{3}$ He burn-fraction TCD reactors pends the attainment of plasma energy balance which is better than predicted by the TRAC-II model used. If it turns out that ignition of $10{ }^{3}$ He burn fraction TCD plasmas is not attainable, it will be necessary to improve the plasma energy balance either by increasing the ${ }^{3} \mathrm{He}$ burn fraction (by recirculating part of the ${ }^{3} \mathrm{He}$ ), or by assisting the plasma with some extra tritium obtained by incorporating some lithium in the blanket, or by externally heating the plasma.

Realization of the potential benefit of the TCD mode of operation also pends the attainment of higher (by about 50\%) $\mathrm{BB}_{\max }^{2}$ than necessary for Cat-D reactors. If the high $\beta_{\max }^{2}$ values are not attainable in tokamak devices, the realization of the TCD mode of operation may depend on the successful development of high beta confinement schemes, such as the compact reversed field pinch devices.

In view of its promise it is recommended that the TCD mode of operation (with its variants) will continue being examined for fuston power reactors as well as for nonelectrical applications of fusion energy. 


\section{IMmODUCTION}

\subsection{The TCD Puel Crele}

The Tritium-Catalyzed Deuteriun (TCD) fusion fuel cycle, illustrated in Fig 1, is a D-D based fuel cycle. More specifically, it is one version of the Partially-Catalyzed-Deuterium (PCD) modes of operation in which all the tritium from the $D(D, n) T$ reaction fuses in the plasma while as much of the ${ }^{3}$ He from the $D(D, P)^{3}$ He reaction which can be recovered from the plasma is placed in the blanket, where it is transmuted into tritium by neutron absorption $[1,2]$. The resulting tritons are fed into the plasma to undergo another $D-T$ reaction.

In a way this TCD moke of operation has a common denominator both with the Cat-D and the Semi-Catalyzed-Deuterium (SCD) modes of operation [2]. Like the SCD mode, it does not fuse the ${ }^{3} \mathrm{He}$ (as is) and, i.ence, is free of a relatively high ${ }^{3} \mathrm{He}$ concentrations in the plasma. Like the Cat-D, the TCD mode of operation fuses one of 1 ts fusion products; but whereas in the Cat-D fuel cycle the ${ }^{3} \mathrm{He}$ fuses as is, in the TCD fuel cycle the ${ }^{3} \mathrm{He}$ is first converted into tritium.

Relative to Cat-D, the TCD mode of operation is free from the need to recirculate the ${ }^{3} \mathrm{He}$; ${ }^{\mathrm{a}}$ thus reducing ${ }^{3} \mathrm{He}$ losses and expenses associated with ${ }^{3} \mathrm{He}$ separation and refueling. Morsover, not having to fuse ${ }^{3} \mathrm{He}$, the TCD plasma can maintain a higher deuterium density (for the same total plasma pressure), thus providing a higher fusion power density [2]. On the other hand, the fraction of the fusion energy being deposited in the plasma is lower for the TCD mode of operation, thus requiring a higher nt value for ignition (or offering a lower fusion energy gain for a given $n \tau$ ).

\footnotetext{
The attainment of the Cat-D mode of operation is $1 i k e l y$ to require recirculating the ${ }^{3} \mathrm{He}$ many times (more than $10[3,4]$ ) in order to fuse it at the rate of its production. Associated with each recirculation is a need to recover the helium from the fuel and ash leaking out of the plasma, and lsotopically separating the ${ }^{3} \mathrm{He}$ from the ${ }^{4} \mathrm{He}$.
} 
Cat-D (Catalyzed Deuterium)

$$
\begin{aligned}
& \mathrm{D}+\mathrm{D} \rightarrow \mathrm{T}+\mathrm{P} \\
& \stackrel{t}{T}+D \rightarrow n(14.1)+H e \\
& \mathrm{D}+\mathrm{D} \rightarrow{ }^{3} \mathrm{He}+\mathrm{n}(2.45)
\end{aligned}
$$

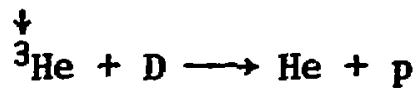

$$
\begin{aligned}
& 6 D \rightarrow 2 p+2 H e+n(2.45)+n(14.1)
\end{aligned}
$$

SCD (Semi Catalyzed Deuterium)

$$
\begin{aligned}
& D+D+T+p \\
& + \\
& T+D+n(14.1)+\mathrm{He} \\
& \mathrm{D}+\mathrm{D}+{ }^{3} \mathrm{He}+\mathrm{n}(1.45) \\
& 5 \mathrm{D}+\mathrm{p}+\mathrm{He}+{ }^{3} \mathrm{He}+\mathrm{n}(2.45)+n(14.1)
\end{aligned}
$$

TCD (Tritium Catalyzed Deuterium)

Similar to SCD but

$$
\begin{array}{r}
\stackrel{+}{3_{\mathrm{He}}+n_{\mathrm{th}}+\mathrm{T}}+\mathrm{p}(\text { In blanket }) \\
+\mathrm{T}+\mathrm{D}+\mathrm{n}(14.1)+\mathrm{He}
\end{array}
$$

FIg. 1. Schematics of D-D based fusion fuel cycles. 
Relative to SCD, the TCD mode of operation offers a significantly higher (by about 80\%) fuston power densfty -- due to the extra D-T reaction provided by each ${ }^{3}$ He atom recovered, and requires a lower $n \tau$ value for ignition [2].

Tabla 1 compares the neutronics and energetics of the three wajor D-D based fusion fuel cycles considered. These fuel cycles are idealized in the sense that they assume that efther all or none of a given fusion product fuses. More on the comparisca of these fuel cycles, as well as on tritiumassisted D-D based (or tritium-lean D-T) plaswas can be found in Refs. 2 and 5.

The TCD mode of operation can, in fact, be viewed also as one version, or 9s a specific design point of tritium-assisted ${ }^{b}$ SCD fuel cycle in which (a) the degree of tritium assistance is determined by the fraction of ${ }^{3}$ ige which is extracted from the plasma; and (b) the tritium is produced from ${ }^{3} \mathrm{He}$ rather than from lithium.

As far as the plasma properties are concerned, the TCD and the corresponding tritium-assisted SCD (to be denoted as SCD-T) plasmas are idcstical. The difference between the TCD and the SCD-T concepts is the blanket systems: whereas the $T C D$ concept calls for the incorporation of ${ }^{3}$ He in the blanket, the SCD-T concept implies (at least in the terminology to be used in this work) incorporating 1ithium in the blanket. The latter scheme is likely to lead to somewhat more difficult blanket design task (but not as difficult as bianket designs for D-T reactors) and to blankets with somewhat reduced safety and maintainability. On the other hand, the SCD-T blankets are expected to have a somewhat higher energy multiplication, as the binding energy released in the ${ }^{6} \mathrm{Li}(\mathrm{n}, a) \mathrm{T}$ reaction is $4.78 \mathrm{MeV}$ versus $0.76 \mathrm{MeV}$ for the ${ }^{3} \mathrm{He}(\mathrm{n}, \mathrm{p}) \mathrm{T}$ reaction. Another potential advantage of the SCD-T mode of operation is the flexibility in the degree of tritiun assistance it can be designed for. Also, the SCD-T fuel cycle wight provide an adequate source of ${ }^{3}$ He for $D-{ }^{3}$ He fusion reactors [2].

$b_{B y}$ tritiun assistance we refer to modes of operation in which tritium is added to the piaswe from sources other than the $D(D, p) T$ and ${ }^{3} H e(n, p) T$ reactions occuring in. the reactor under consfderation. 
TABLE 1

Neutron and Energy Balance of Prime Ideal Fusfon Fuel Cycles

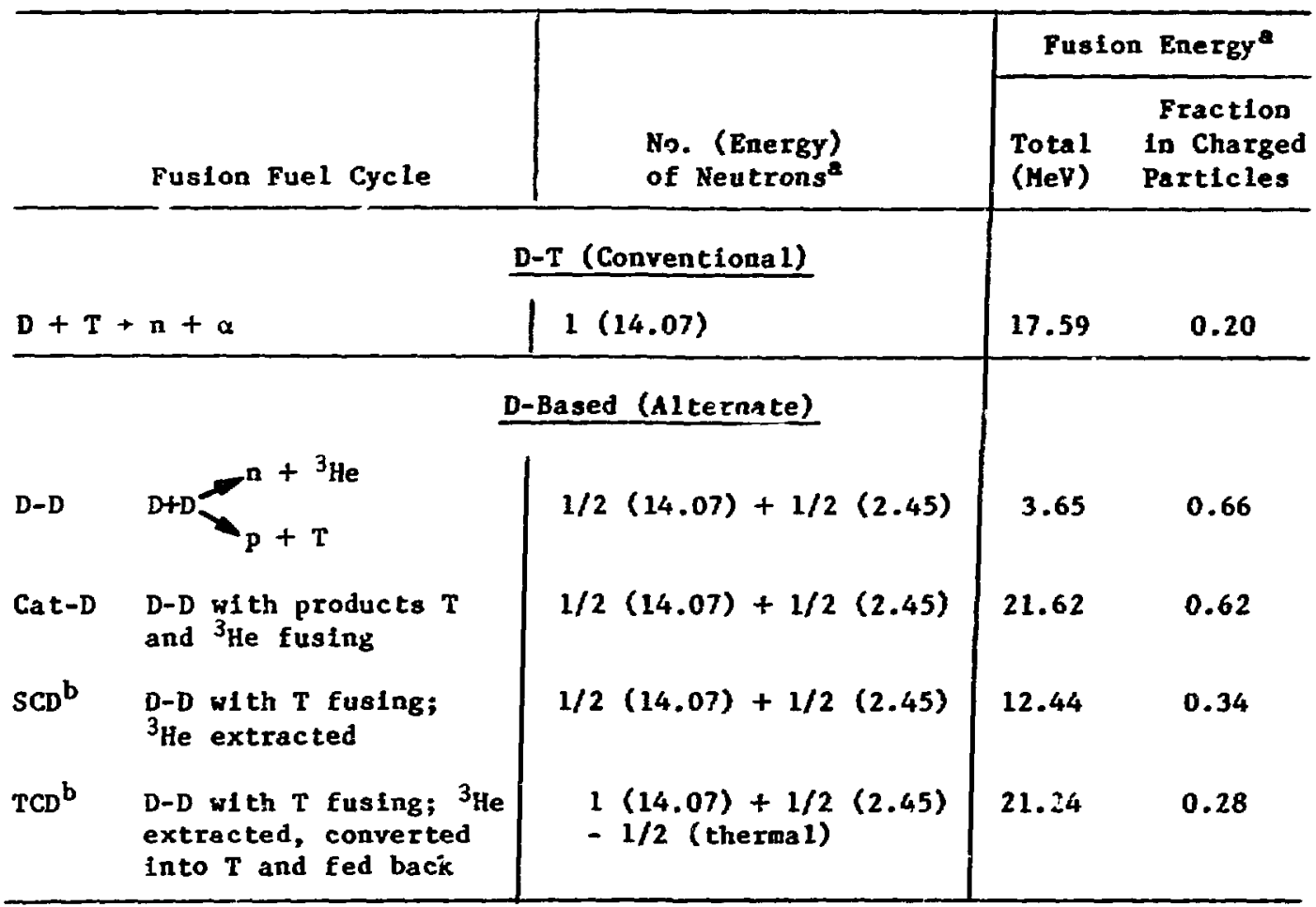

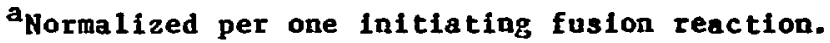

${ }^{b}$ This SCD fuel cycle is an Idealized semi-catalyzed deuterium cycle in which all the tritlum and none of the ${ }^{3} \mathrm{He}$ produced in the D-D reactione is assumed to fuse in the plasma. Similarly, the TCD is the idealized version of the SCD fuel cycle in which all the ${ }^{3}$ He from the $D(D, n)^{3}$ He reaction is converted into tritium, which is fed back to the plasma and fuses in it.

\subsection{D-D Based Reactor Studies - Reriew}

Following the pioneering work of Mils [6], most of the D-D based fusfon power reactor studies (based on magnetic sonfinenent) considered the Cat-D fuel cycle $[3,4,7-12]$. The SCD fusion fuel cycle was first considered in the context of fusion-fission hybrid reactors [13-15].

The TCD mode of operation was first proposed by Owens and Impink [16]. Their incentive was to avoid the need for separating ${ }^{3} \mathrm{He}$ from ${ }^{4} \mathrm{He}$, so as to 
reduce expenses and loss of ${ }^{3} \mathrm{He}$ (relative to the Cat-D mode of operation). Following Owens and Impink, Post considered the TCD fuel cycle for mirror reactors [1]], offering it as a substitute for the D-T cycle alred at eliminating 11 thium blanket and reducing the tritfum inventory. He restricted his study to very high temperature, low-Q mirrors.

Following the introduction of the concepts of partially-catalyzed and tritium-assisted modes of operation [18,19] a number of reactor studies based on such modes of operation were undertaken. These include the D-D/D-T tokamaks designed by the HIT group [20,21], the D-D based tandem mirror study by UCLA [11], the ${ }^{3}$ He-lean Cat-D tokamak study by SAI [22], and the tritium-lean tokamaks recently studied by ARL $[23,24]$.

None of the above-mentioned studies considered TCD reactors. Whereas the Owens and Impink examination [16] of the TCD concept concentrated on the issue of ${ }^{3}$ He handling, Post examined [17] prinarily the issue of fusion reaction balance. Following a prelfminary assessmant of the promise of the TCD mode of operation for nonelectrical applications $[2,25]$ of fusion, the propsect of this mode of operation for fissile fuel production was recently studied (5, 26]. Even though still prelirinary in nature, this study examined the performance of both the fusion driver and the blanket, as well as the economics of the TCD fusion breeder. The present work carries out a sallar assessment, but as applied to a TCD fusion power reactor.

\subsection{Objectives, Scope, and Approach}

The purpose of the present work is to assess the pronise of TCD tokanaks. The assessment is done by comparing the performance of TCD tokanaks with the performance of D-T, Cat-D, as well as Cat-D-T (f.e., tritium-assisted Cat-D) and SCD-T tokamaks. Being a short study, the investigation is limited in scope and $i s$, necessarfly, preliminary in nature. It makes use of the extensive data base and design tools developed in the AKL tokanak design studies $[4,23,27]$.

There are three parts to the work: blanket neutronics study (Sec. 2); a paranetric study of TCD tokanaks and their econonic analysis (Sec. 3), and an assessment of potential for further improvement in the dssign and performance of TCD reactors (Sec. 4). Additional considerations associated with the realization of the TCD wode of operation and with nonelectrical applications of TCD (and other partially catalyzed) reactors are presented in Sec. 5. 


\section{DLAICT STODT}

\subsection{Study Conls and Stratery}

The blanket study is almed at estimating the (1) ${ }^{3}$ He inventory required for converting the ${ }^{3} \mathrm{He}$ into tritium (at the rate of the ${ }^{3} \mathrm{He}$ production); and (2) blanket energy autiplication attainable. The blanket design goals include minimizing th: ${ }^{3} \mathrm{He}$ Inventory and maximfing the blanket energy multiplication. These two goais ay not be attained simultanecusiy: minimal ${ }^{3} \mathrm{He}$ Inventory is expected in well-moderaced (1.e., soft spectrua) blankets having a Low structure volume fraction (since the structural aterial competes with ${ }^{3}$ He for the neutrons). Maximizing the energy nutiplication, on the other hand, calls for maximizing the neutron absorption probability in the structural materials (or, in general, In materials offering a release of a relatively large amount of binding energy per neutron absorption). Thus, the blanket design is a subject for optimization. Such an optimization is beyond the scope of this work; instead, we shall identify a range of attainable blanket energy multiplication and ${ }^{3}$ He inventory.

A single type of blanket -- that conceived for the WILDCAT tokanak [4], is considered for the present study. The blanket constituents are PG (a type of austenitic stainless steel), water and ${ }^{3}$ He (Instead of liquid lithium or $\mathrm{Li}_{2} \mathrm{O}$ used In Ref. 23). The ${ }^{3} \mathrm{He}$ is assumed to be confined to the outer blanket, thus enabling us to design the inboard blanket/shield to have a minimal thickness (1.e., having it free of void). Confining the ${ }^{3}$ He-to-tritiun converter to the outer blanket does not at all impair the reactor performance as only a small fraction (of the order of one-third) of the fusion neutrons need be absorbed by the ${ }^{3} \mathrm{He}$ for the TCD node of operation. Eighty-five per cent of the fusion neutrons are assuned to reach the outer blanket.

The prifurmance of the outer blanket is estimated using a one-dimensional cylindrical geometry, with the cylinder axis at the center of the plaswa chanber (located $2.2 \mathrm{~m}$ from the first wall). The 1-cm thick first wall is taken (after Ref. 23) to be of $65 \% \mathrm{PCA}$ and $35 \% \mathrm{H}_{2} \mathrm{O}$. Following the first wall is a $70-\mathrm{cm}$ thick uniform composition blanket which is followed by a 150-cin thick uniform composition shield ade of 60\% Fe-1422, 35\% B 4 (at 95\% theoretical density) and $5 \% \mathrm{H}_{2} \mathrm{O}$. An Isotropic source of fusion neutrons is taken to be uniformly distributed throughout the plasas region (not including the 20-ca 
thick annular scrope-off region adjacent to the first wall. The $\mathrm{PCA}, \mathrm{H}_{2} \mathrm{O}$, and ${ }^{3}$ He volume fractions in the blanket reglon are varled paranetrically. The ${ }^{3} \mathrm{He}$ Is assumed to have an atomic density of $6.9 \times 10^{24}$ atoms/ca ${ }^{3}$ corresponding, for example, to $50 \mathrm{~atm}$ and $300^{\circ} \mathrm{C}$. The blankets are taken (for the calculations) to have a uniform composition even though the results are analyzed as if the ${ }^{3} \mathrm{He}$ was confined to only the front part of the outer blanket volume (starting from the first wall).

All the calculations, are performed with the one-dimensional transport code ANISN [28] using the 46-neutron, 21-photon group constants derived fron the VITAMIN-C [29] and the MCKLIB [30] 11braries. Hot having ${ }^{3}$ He kerma factors in the MACKLIB library, the contrfbution of 3 He to the total blanket energy multiplication is estimated by assuming that the ${ }^{3}$ He contribution to the blanket energy comes via the ${ }^{3} \mathrm{He}(\mathrm{n}, \mathrm{p}) \mathrm{T}$ reaction only, and that this contribution amounts to $0.765 \mathrm{MeV}$ per reaction. All the nucleonic calculations are performed with the $\mathrm{P}_{3}-\mathrm{S}_{8}$ transport approximation.

\subsection{Tritiu Ereeding Requirements}

Consider an idealized TCD reactor (which suffers no losses of ${ }^{3}$ He atons, tritons, and neutrons) in which a fraction $\alpha$ of the ${ }^{3}$ He atoms produced in the plasms escapes the plasma without fusion. What tritium breeding ratio (TBR) aoes the blanket need to be designed for?

Let $u s$ denote by $\gamma_{D-T}$ and $Y_{D-D}$ the number of tritons to be produced per, respectively, a D-T and $a$ D-D fuston neutron and by $N$ the ratio of $D-T$ to $D-D$ neutrons produced in the reactor. Then the ${ }^{3} \mathrm{He}$-to-tritium conversion requirement implies that

$$
Y_{D-D}+N Y_{D-T}=a
$$

Realizing that

$$
H=\alpha+\langle\alpha v\rangle_{D-D_{\mathrm{T}}}\left\langle\langle\alpha v\rangle_{\mathrm{D}-\mathrm{D}_{\mathrm{n}}} \equiv \alpha+u\right.
$$

where $\langle\sigma v\rangle_{D}-D_{T}$ and $\langle\sigma \gamma\rangle_{D}-D_{n}$ are the reactivity for, respectively, the $D(D, p) T$ and the $D(D, n)^{3}$ He reactions, one obtains

$$
Y_{D-D}+(\alpha+u) Y_{D-T}=\alpha
$$


or

$$
Y_{D-D}=\alpha /[1+(\alpha+u) e]
$$

where

$$
\text { e } \equiv Y_{D-T} / Y_{D-D}
$$

depends on the specific blanket design characteristics. The parameter $u$, on the other hand, depends on the plasma temperature; for the temperature range consfdered in this work, a typical value of a is 0.9 .

Table 2 1llustrates the tritlun breeding requirements from blankets for TCD fusion reactors characterized by different values of $e$ and two values of

TABLE 2

Tritiun Breeding Requirements for TCD Blankets * as a Function of $e \equiv \Upsilon_{D-T} / \gamma_{D-D}$

\begin{tabular}{l|c|c|c|c}
\hline \multirow{2}{*}{} & \multicolumn{3}{|c}{ Blanket Coverage } \\
\cline { 2 - 5 } & \multicolumn{2}{|c}{$100 \%$} & \multicolumn{2}{c}{$85 \%$} \\
\cline { 2 - 5 } 0 & $Y_{D-D}$ & $Y_{D-T}$ & $Y_{D-D}$ & $Y_{D-T}$ \\
\hline 0.5 & 0.474 & 0.237 & 0.557 & 0.279 \\
0.6 & 0.433 & 0.260 & 0.509 & 0.305 \\
0.7 & 0.398 & 0.279 & 0.469 & 0.328 \\
0.8 & 0.369 & 0.295 & 0.434 & 0.347 \\
0.9 & 0.344 & 0.309 & 0.404 & 0.364 \\
1.0 & 0.321 & 0.321 & 0.378 & 0.378 \\
1.1 & 0.302 & 0.332 & 0.355 & 0.391 \\
1.2 & 0.285 & 0.342 & 0.335 & 0.402 \\
1.3 & 0.269 & 0.350 & 0.317 & 0.412 \\
1.4 & 0.256 & 0.358 & 0.301 & 0.421 \\
1.5 & 0.243 & 0.365 & 0.286 & 0.429 \\
\hline
\end{tabular}

*Assuning $\alpha=0.9$ and $u=0.9$. 
blanket coverage efficiencies -- 100\% (an idealized situation) and $85 \%$ (representing tokamak designs in which the ${ }^{3}$ He-to-tritiue converter is confined to the outer blanket only). It is observed (consider, for example, the $e=1.0$ case) that the TBR required for the TCD mode of operation is on the order of one-thixd (1.e., approximately one neutron need be absorbed in ${ }^{3} \mathrm{He}$ per every three fusion neutrons).

\subsection{He Inventory Eequirements}

The tritium breeding ability of the $\mathrm{PCA}: \mathrm{H}_{2} \mathrm{O}:{ }^{3} \mathrm{He}$ blankets considered, and Its dependence on the blanket conposition and on the fusion neutron type are 1llustrated in Figs. 2 through 5 and in Table 3 . Consider, first, the effect of variation in the $\mathrm{PCA}: \mathrm{H}_{2} \mathrm{O}$ volume fraction with fixed ${ }^{3} \mathrm{He}$ inventory -- Figs. 2 and 3. It is observed that:

- The lower the PCA volume fraction, the higher becomes the tritium breeding ability ci the blanket. This trend is attribited to the reduced competition for neutrons the ${ }^{3}$ He has, when the PCA concentration is reduced.

- The maximal TBR of $D-T$ neutrons is higher than that of D-D neutrons when the PCA volume fraction is relatively high, but lower than that of D-D neutrons for the low PCA volume fraction blanket. This is due to the fact that with the high $\mathrm{PCA}$ concentration, the 14-MeV neutron has a non-negligible probability for inducing $(n, 2 n)$ reactions, thus augmenting the tritium production probability. As the PCA volume fraction decreases, the probability for the $(n, 2 n)$ reactions decresses as well. The 14-HeV neutron has, however, a higher probabillty for being absorbed while slowing down. Hence, the tritiun breeding ratio for the $2.45-\mathrm{HeV}$ neutron becomes higher than that for the 14-MeV neutron.

- Most of the ${ }^{3}$ He-to-tritium conversion caused by the D-D neutrons takes place within the front 20 to $25 \mathrm{~cm}$ in the blanket (measured from the source side). The approach to the asymptotic breeding ratio is more gradual in the case of the D-T neutrons. This difference reflects the higher penetrability (longer mean-free path) of the D-T neutrans. 

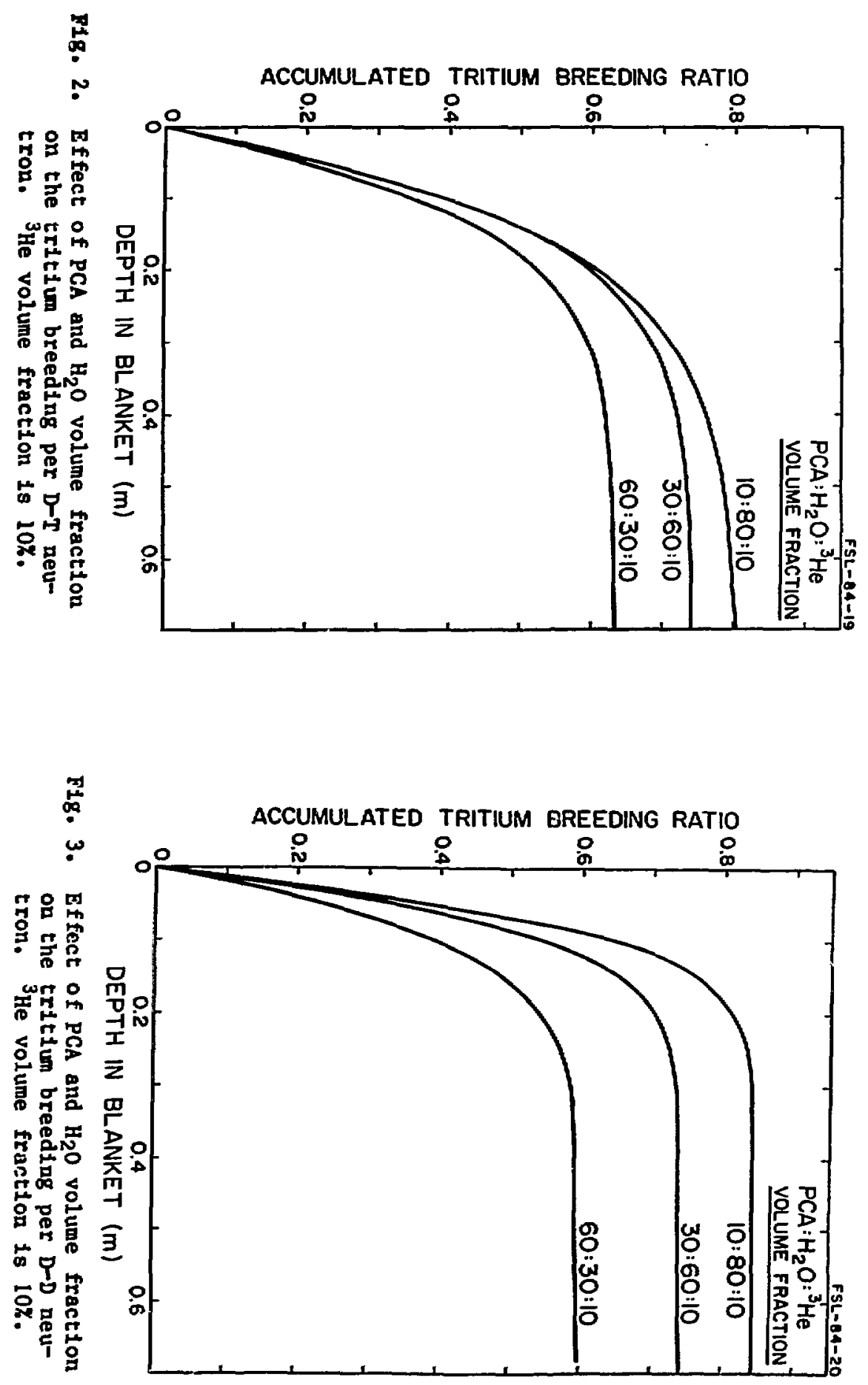

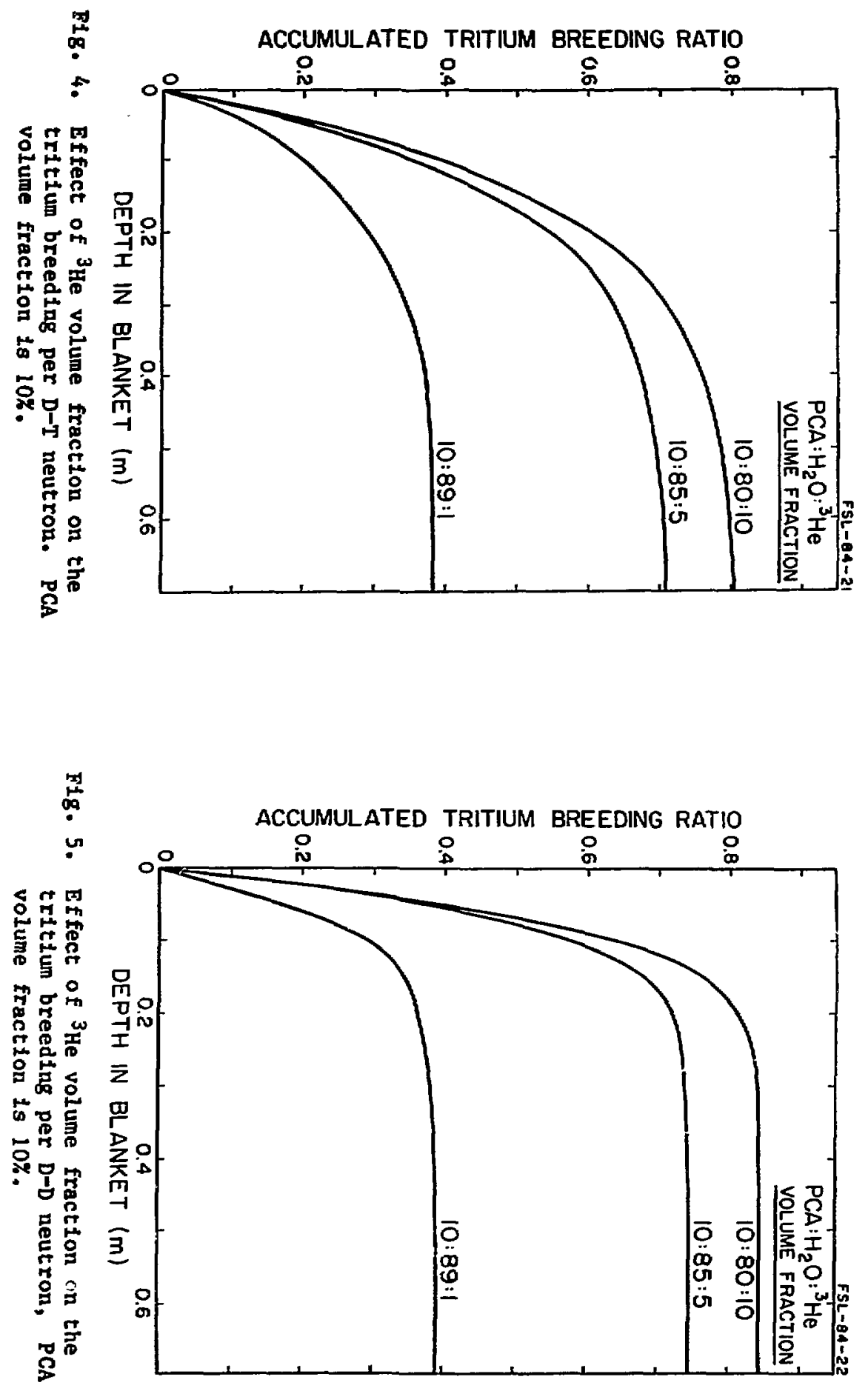
TABLE 3

Tritiu Breeding Ratio and Energy Hultiplication of $\mathrm{PCA}: \mathrm{H}_{2} \mathrm{O}:{ }^{3} \mathrm{He}$ Blankets

\begin{tabular}{|c|c|c|c|c|c|c|c|}
\hline \multirow{2}{*}{$\begin{array}{l}\text { Case } \\
\text { No. }\end{array}$} & \multicolumn{3}{|c|}{$\begin{array}{c}\text { Blanket Composition } \\
(\mathrm{vol}-\mathrm{z})\end{array}$} & \multicolumn{2}{|c|}{$\begin{array}{c}\text { Tritiun Breeding } \\
\text { Ratio }\end{array}$} & \multicolumn{2}{|c|}{$\begin{array}{l}\text { Blanket Energy } \\
\text { Hultiplicationb }\end{array}$} \\
\hline & PCA & $\mathrm{H}_{2} \mathrm{O}$ & ${ }^{3} \mathrm{He}^{\mathrm{a}}$ & $D-T$ & D-D & $D-T$ & D-D \\
\hline AO & 90 & 10 & 0 & 0. & 0. & 1.509 & 4.405 \\
\hline$A 1$ & 60 & 10 & 30 & 0.7550 & 0.6992 & 1.079 & 2.136 \\
\hline$A 2$ & 60 & 30 & 10 & 0.6328 & 0.5959 & 1.151 & 2.152 \\
\hline$A 3$ & 30 & 10 & 60 & 0.8778 & 0.8490 & 0.909 & 1.566 \\
\hline$A 4$ & 30 & 60 & 10 & 0.7419 & 0.7389 & 1.043 & 1.945 \\
\hline 15 & 10 & 80 & 10 & 0.8035 & 0.8439 & 1.038 & 1.564 \\
\hline A6 & 10 & 85 & 5 & 0.7139 & 0.7443 & 1.075 & 1.793 \\
\hline$A 7$ & 10 & 89 & 1 & 0.3821 & 0.3897 & 1.203 & 2.593 \\
\hline A8 & 20 & 79 & 1 & 0.3010 & 0.3016 & 1.280 & 3.054 \\
\hline$A 9$ & 20 & 75 & 5 & 0.6567 & 0.6675 & 1.117 & 2.087 \\
\hline $\mathbf{A}$ & 20 & 70 & 10 & 0.7733 & 0.7893 & 1.062 & 1.764 \\
\hline$A B$ & 30 & 69 & 1 & 0.2488 & 0.2452 & 1.328 & 3.345 \\
\hline $\mathbf{A C}$ & 30 & 65 & 5 & 0.6065 & 0.6029 & 1.151 & 2.331 \\
\hline
\end{tabular}

a ${ }^{3}$ He density is $6.877 \times 10^{20}$ atoms/cc.

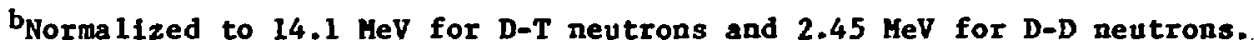

Figures 4 and 5 show the tritium breeding ability of low PCA content blankets; the PCA volume fraction is probably close to its minimal practical 1imit. As there is a very small probability for $(n, 2 n)$ reactions in these blankets, the tritium breeding ratio attainable by a D-D neutron surpasses that attainable by a D-T neutron. Horeover, due to the penetrability of the D-T neutrons, their tritium production spans over most of the blanket rolume, whereas most of the critium production by D-D neutrons occurs within the first $20 \mathrm{~cm}$ or so.

An estimate of the ${ }^{3}$ He inventory required for attaining a desirable tritlum breeding ratio in the different blankets can readily be deduced fron Figs. 6 and 7 , In which the ${ }^{3}$ He inventory is expressed in terms of an "effective ${ }^{3} \mathrm{He}$ zone thickness". There is a one-to-one correspondence between this effective 

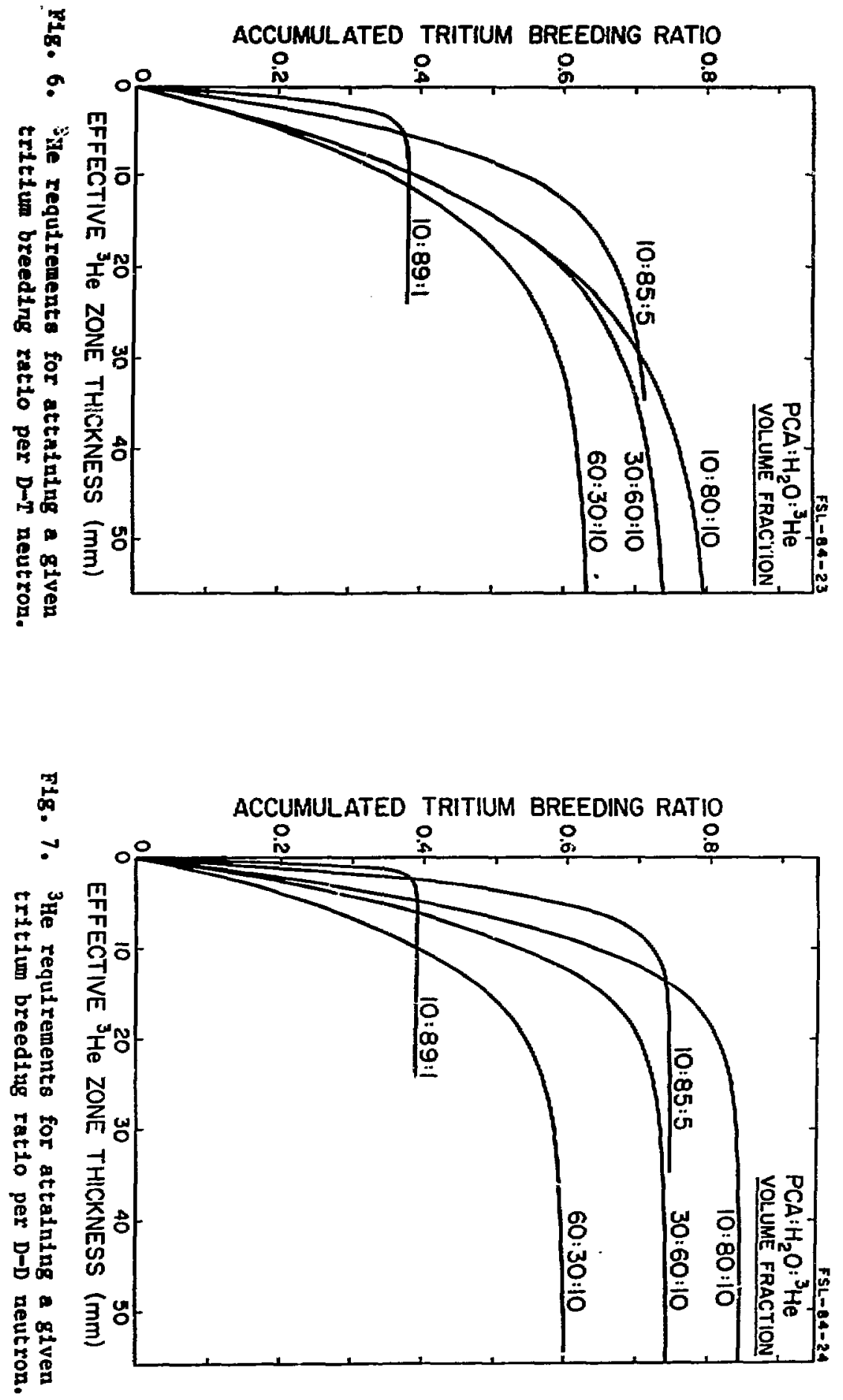
${ }^{3}$ He thickness and the "depth In blanket" scale of Figs. 2 to 5 supplemented by the ${ }^{3}$ He volume fraction in the specific blanket under consideration.

Consider, for example, a TCD reactor operating with $a=0.9$ and using a $P C A: \mathrm{H}_{2} \mathrm{O}:{ }^{3} \mathrm{He}=10: 85: 5$ blanket "seeing" $85 \%$ of the fusion neutrons. To account for the neutrons which do not take part in tritium production, we impose an effective $a$ value of $0.9 / 0.85 \simeq 1.059$; $1 . e$. , we require $85 \%$ of the neutrons actually released (in fusion reactions) per ${ }^{3} \mathrm{He}$ aton produced, to convert $1.059{ }^{3}$ He atoms into tritium. Using the results of Figs. 6 and 7 we find (by trial and error), that the effective ${ }^{3}$ He layer needed is approximately $3.8 \mathrm{~mm}$, the corresponding $Y_{D-T} \approx 0.30$ (Fig. 6) and $Y_{D-D} \approx 0.51$ (Fig. 7) assuming a $u$ of 0.9 . This effective ${ }^{3}$ He zone thickness corresponds to 4.34 moles of ${ }^{3}$ He per square meter of first wall area. When occupying $5 \%$ of the blanket volume, the ${ }^{3}$ He containing zone should span the first $7.5 \mathrm{~cm}$ of the blanket.

Carrying out a similar analysis for the $P C A: H_{2}{ }^{0}{ }^{3}$ He $=10: 89: 1$ lanket gives $Y_{D-T}=0.37$ and $Y_{D-D} \approx 0.39$ pertaining to an effective 3 He zone thickness of $4.8 \mathrm{~mm}$, corresponding to 5.48 moles ${ }^{3} \mathrm{He} / \mathrm{m}^{2}$ first wall area. Similarly, for the PCA:H $\mathrm{H}_{2} 0:{ }^{3} \mathrm{He}=30: 60: 10$, blanket $Y_{D-T} \approx 0.32, Y_{D-D} \approx 0.45$, and the effective ${ }^{3} \mathrm{He}$ zone thickness is $7.4 \mathrm{~mm}$, or 8.45 moles ${ }^{3} \mathrm{He} / \mathrm{m}^{2}$ first wall area.

\subsection{Blanket Bnergy Multiplication}

of the PCA:H $\mathrm{O}^{3} \mathrm{He}$ blanket constituents, the $\mathrm{PCA}$ provides the highest (-7.9 MeV [31]), whereas ${ }^{3}$ He provides the lowest (0.76 MeV) binding energy release. Thus, maximizing the energy multiplication implies designing the blanket to maximize the capture, in PCA, of those neutrons not needed for tritium production.

The energy multiplication of the $D-T$ and $D-D$ neutrons in the specific blankets studied is summarized in Table 3, while Tables 4 and 5 give a breakdown of the energy deposition in these blankets (including the first wall). It turns out that the energy multiplication of all these PGA:H ${ }_{2}{ }^{3}{ }^{3} \mathrm{He}$ blankets can be conventently expressed parametrically -- the parameter being the ${ }^{3} \mathrm{He}-$ to-PCA volume ratio; this parametric representation is illustrated in Fig. 8 , which represents all the blankets of Table 3 . 
TABLE 4

Breakdown of Energy Deposition in PCA $: \mathrm{H}_{2} \mathrm{O}:{ }^{3} \mathrm{He}$ Blankets Driven by D-T Neutrons

\begin{tabular}{|c|c|c|c|c|c|}
\hline \multirow[b]{2}{*}{$\begin{array}{l}\text { Case } \\
\text { No. }\end{array}$} & \multirow{2}{*}{$\begin{array}{c}\begin{array}{c}\text { Blanket } \\
\text { Composition } \\
(\text { vol- } \%)\end{array} \\
\text { PCA } / \mathrm{H}_{2} \mathrm{O} /{ }^{3} \mathrm{He}\end{array}$} & \multicolumn{4}{|c|}{$\begin{array}{l}\text { Energy Depusition } \\
(\mathrm{MeV} / \mathrm{n})\end{array}$} \\
\hline & & $\begin{array}{l}\text { First } \\
\text { Hal1 }\end{array}$ & $\begin{array}{c}\text { Blanket } \\
\text { Hithout } \\
{ }^{3} \mathrm{He}\end{array}$ & ${ }^{3} \mathrm{He}$ & Total \\
\hline AO & $90 / 10 / 0$ & 2.004 & 19.218 & 0. & 21.223 \\
\hline A1 & $60 / 10 / 30$ & 1.669 & 12.935 & 0.570 & 15.174 \\
\hline A2 & $60 / 30 / 10$ & 1.682 & 14.010 & 0.484 & 16.176 \\
\hline A3 & $30 / 10 / 60$ & 1.529 & 11.257 & 0.672 & 13.458 \\
\hline A4 & $30 / 60 / 10$ & 1.526 & 13.141 & 0.568 & 15.235 \\
\hline A5 & $10 / 80 / 10$ & 1.367 & 12.617 & 0.615 & 14.599 \\
\hline A6 & $10 / 85 / 5$ & 1.429 & 13.140 & 0.546 & 15.115 \\
\hline A7 & $10 / 89 / 1$ & 1.642 & 14.975 & 0.293 & 16.910 \\
\hline A8 & $20 / 79 / 1$ & 1.745 & 16.017 & 0.230 & 17.992 \\
\hline A9 & $20 / 75 / 5$ & 1.530 & 13.668 & 0.502 & 15.700 \\
\hline$A A$ & $20 / 70 / 10$ & 1.457 & 12.881 & 0.592 & 14.930 \\
\hline $\mathrm{AB}$ & $30 / 69 / 1$ & 1.800 & 16.681 & 0.190 & 18.671 \\
\hline $\mathrm{AC}$ & $30 / 65 / 5$ & 1.602 & 14.121 & 0.464 & 16.187 \\
\hline
\end{tabular}


TABLE 5

Breakdown of Energy Deposition in PCA : $\mathrm{H}_{2} \mathrm{O}:{ }^{3} \mathrm{He}$ Blankets Driven by D-D Neutrons

\begin{tabular}{|c|c|c|c|c|c|}
\hline \multirow[b]{2}{*}{$\begin{array}{l}\text { Case } \\
\text { No. }\end{array}$} & \multirow{2}{*}{$\begin{array}{c}\begin{array}{c}\text { Blanket } \\
\text { Composition } \\
(\text { vol-z) }\end{array} \\
\mathrm{PCA} / \mathrm{K}_{2} \mathrm{O} /{ }^{3} \mathrm{He}\end{array}$} & \multicolumn{4}{|c|}{$\begin{array}{l}\text { Energy Deposition } \\
(\mathrm{HeV} / \mathrm{r})\end{array}$} \\
\hline & & $\begin{array}{l}\text { First } \\
\text { Wall }\end{array}$ & $\begin{array}{l}\text { Blanket } \\
\text { Without } \\
\text { 3he }\end{array}$ & ${ }^{3} \mathrm{He}$ & Total \\
\hline AO & $90 / 10 / 0$ & 0.921 & 9.870 & 0. & 10.791 \\
\hline A1 & $60 / 10 / 30$ & 0.588 & 4.116 & 0.535 & 5.233 \\
\hline$A 2$ & $60 / 30 / 10$ & 0.632 & 4.921 & $0 .-56$ & 6.009 \\
\hline A3 & $30 / 10 / 60$ & 0.460 & 2.727 & 0.650 & 3.837 \\
\hline A4 & $30 / 60 / 10$ & 0.540 & 3.660 & 0.566 & 4.766 \\
\hline A5 & $10 / 80 / 10$ & 0.446 & 2.741 & 0.646 & 3.833 \\
\hline A6 & $10 / 85 / 5$ & 0.546 & 3.278 & 0.570 & 4.394 \\
\hline A7 & $10 / 89 / 1$ & 0.870 & 5.184 & 0.298 & 6.352 \\
\hline$A B$ & $20 / 79 / 1$ & 0.922 & 6.329 & 0.231 & 7.482 \\
\hline A9 & $20 / 75 / 5$ & 0.612 & 3.991 & 0.511 & 5.114 \\
\hline $\mathbf{A A}$ & $20 / 70 / 10$ & 0.500 & 3.217 & 0.604 & 4.321 \\
\hline$A B$ & $30 / 69 / 1$ & 0.924 & 7.083 & 0.188 & 8.195 \\
\hline$A C$ & $30 / 65 / 5$ & 0.651 & 4.599 & 0.461 & 5.711 \\
\hline
\end{tabular}




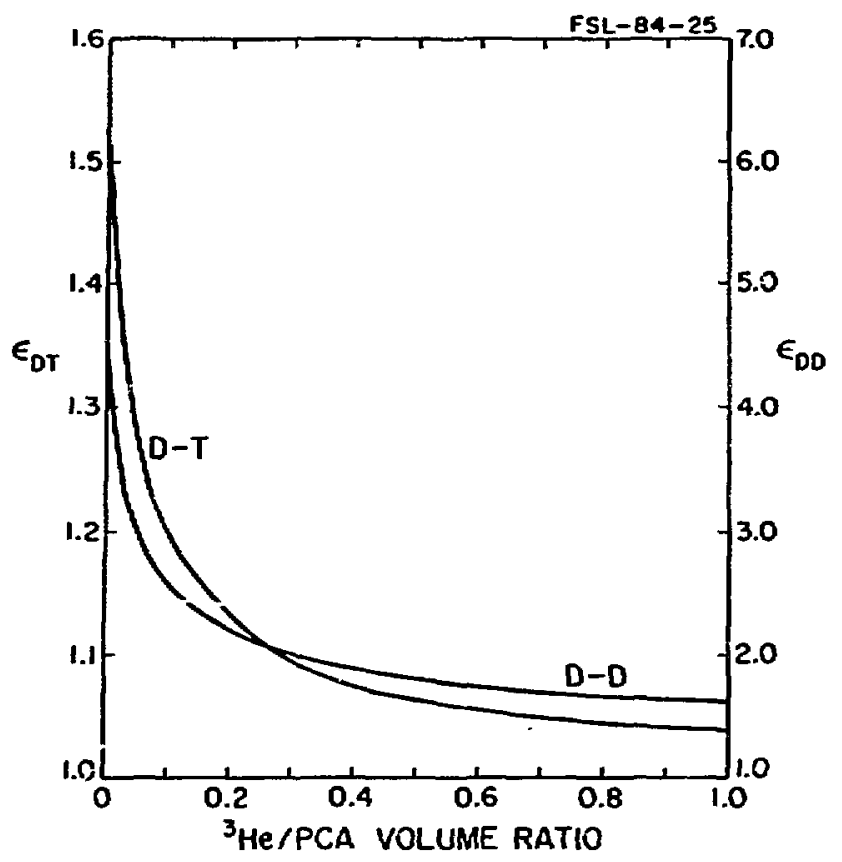

Fig. 8. Effect of ${ }^{3}$ He-to-PCA volume ratio on the energy multiplication of $D-T\left(\epsilon_{D}-T\right)$ and $D-D$ $\left(E_{D}-D\right)$ neutrons for $P C A: \mathrm{H}_{2} \mathrm{O}:{ }^{3} \mathrm{He}$ blankets.

It is found that the energy multiplication is almost irdependent, in the range of blankets considerd, of the water volume fraction; it depends primarily on the amount of ${ }^{3} \mathrm{He}$ relative to the amount of PCA (represented by the ${ }^{3} \mathrm{He} / \mathrm{PCA}$ volume ratio), which is closely proportional to the ${ }^{3} \mathrm{He}$-to-PCA neutron capture probability.

Consider a given blanket (say one of the blankets of Table 3 ) the tritium breeding ratio of which is adjusted to the desirable value by selecting the proper ${ }^{3} \mathrm{He}$ inventory. For each neutron saved from ${ }^{3}$ He capture, the blanket gains $7.14 \mathrm{MeV}$ - the difference beween the binding energy release per neutron capture in ${ }^{3} \mathrm{He}$ and PCA. Denoting the fiston neutron energy by $E_{n}(\mathrm{MeV})$, the tritium breeding dependence of the total energy deposited per fusion neutron $\left(\Delta_{v}\right)$ in a given blanket can be estivated by assuning a one-to-one correspondence between neutron capture in the ${ }^{3} \mathrm{He}$ and PCA:

$$
W_{n}=E_{n} \varepsilon_{0}+(7.9-0.76) \Delta \Upsilon_{n},
$$


where

$$
\Delta \gamma_{\mathbf{n}} \equiv \gamma_{\text {no }}-\gamma_{\mathbf{n}}
$$

In which $\gamma_{\mathrm{no}}$ is the $\gamma_{\mathrm{n}}$ value wiculated for the reference blanket, and $\varepsilon_{0}$ is the energy multiplication in the reference blanket. Dividing through by $E_{n}$ and rearranging we obtain:

$$
\varepsilon=\left[\varepsilon_{0}+\frac{7.14}{E_{n}} Y_{n o}\right]-\frac{7.14}{E_{n}} Y_{n},
$$

1.e., a linear relationship between the energy multiplication and the tritiun breeding ratio.

Figure 9 illustrates the $Y_{n}$ dependence of the energy aultiplication predicted this way for selected blankets. The small displacement between the lines of the different blankets reflects the difference in their water volume fraction ... i.e., in the probability for neutron capture in water as well as for the $(n, 2 n)$ neutron multiplication in PCA. The data of Fig. 9 or Eq. (8) is used to deduce the energy multiplication of a blanket of a given type (characterized, say, by a given $\mathrm{PCA}$ and $\mathrm{H}_{2} \mathrm{O}$ volumes) designed to provide a desirable tritium breeding ratio.

\subsection{Illustrative TCD Blanket Characteristics}

Table 6 provides, In way of summary, 111ustrations of characteristics of selected blankets designed to provide the ${ }^{3} \mathrm{He}$-to-tritium transmutation rate necessary for the TCD mode of operation, assuming that the blanket "coverage effictency" is $85 \%$ (see Sec. 2.1). The tritium breeding ratio requirements along with the effective ${ }^{3}$ He zone thickness are decermined from Figs. 6 and 7 along with Eqs. (4) and (5), in which $\alpha$ ts taken to be $0.9 / 0.85 \neq 1.059$. The corresponding blanket energy multiplications are deduced from Fig. 9 or from the data of Tables 3 and 6, with the help of Eq. (8). 


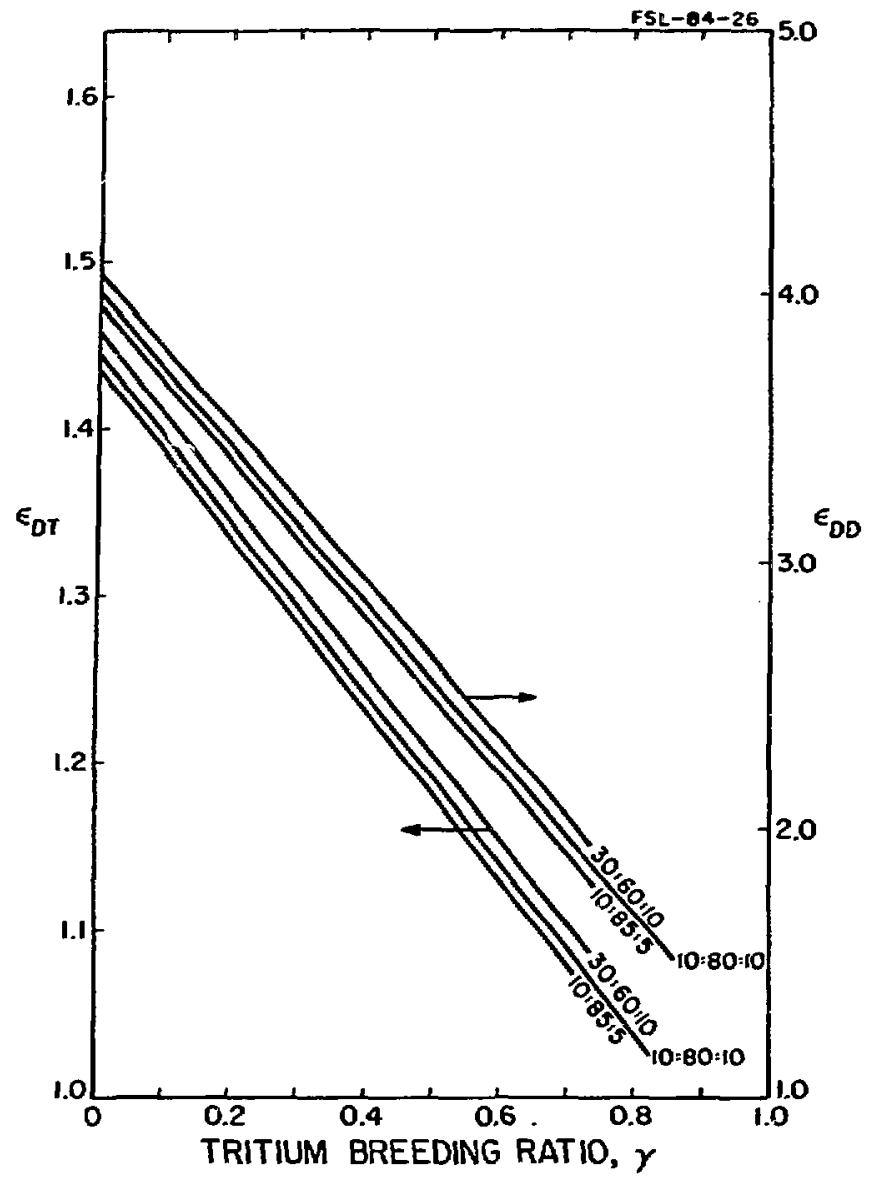

Fig. 9. Effect of tritiun breeding ratio on the energy multiplication $(\varepsilon)$ attainable from $\mathrm{PCA}: \mathrm{H}_{2} \mathrm{O}:{ }^{3} \mathrm{He}$ blankets.

\subsection{Discussion}

of the blankets cousidered in Table 6, the PCA: $\mathrm{H}_{2} \mathrm{O}=10: 85$ blanket offers the lowest ${ }^{3} \mathrm{He}$ inventory. Assuning that the first wall area of a full-size TCD tokanak (after Case 8 of Ref. 23) is of the order of $900 \mathrm{~m}^{2}$, and that the needed out-of-blanket inventory of ${ }^{3} \mathrm{Be}$ is likely to be of the order of $50 \%$ of the ion-blanket Inventory [33] the total ${ }^{3} \mathrm{He}$ inventory called for is approximately $17.6 \mathrm{~kg}$. At a price of $\$ 750 / \mathrm{g}{ }^{3} \mathrm{He}$, the capital required for purchasing the ${ }^{3} \mathrm{He}$ is 13.2 \$M. This is less than 17 of the total capital cost of a WILDCAT-type reactor $[4,23]$. 
TABLE 6

${ }^{3}$ He Inventory Requirenents for, and Selected Characteristics of PCA: $\mathrm{H}_{2} \mathrm{O}:{ }^{3} \mathrm{He}$ Blankets for TCD Mode of Operation

\begin{tabular}{|c|c|c|c|}
\hline \multirow[b]{2}{*}{ Characteristic } & \multirow{2}{*}{$\frac{\text { Blaniet }}{10: 89}$} & \multicolumn{2}{|c|}{ PCA: $\mathrm{H}_{2} \mathrm{O}$ Volume Ratio } \\
\hline & & $10: 85$ & $30: 60$ \\
\hline Fraction of ${ }^{3}$ He saved & 0.9 & 0.9 & 0.9 \\
\hline Ratio of $\mathrm{D}-\mathrm{T}$ to $\mathrm{D}-\mathrm{D}_{\mathbf{n}}$ & 1.8 & 1.8 & 1.8 \\
\hline Blanket coverage efficiency $(z)$ & 0.85 & 0.85 & 0.85 \\
\hline TBR needed & & & \\
\hline D-T neutron & 0.37 & 0.30 & 0.32 \\
\hline$D-D$ neutron & 0.39 & 0.51 & 0.45 \\
\hline Blanket energy multiplication ${ }^{a}$ & & & \\
\hline D-T neutron & 1.208 & 1.284 & 1.297 \\
\hline D-D neutron & 2.593 & 2.476 & 2.787 \\
\hline $\begin{array}{l}\text { B1anket energy generation }{ }^{b} \text { per } \\
\text { D-D neutron (Me:!) }\end{array}$ & 10.95 & 12.35 & 13.27 \\
\hline${ }^{3}$ He effective zone thickness (ca) & 0.48 & 0.38 & 0.74 \\
\hline${ }^{3}$ He speciflc inventory (moles/n ${ }^{2}$ ) & 5.48 & 4.34 & 8.45 \\
\hline${ }^{3}$ He spectfle cost $\left(10^{3} \$ / \mathrm{m}^{2}\right)^{\mathrm{C}}$ & 12.33 & 9.77 & 19.01 \\
\hline
\end{tabular}

an blanket sections which contain the ${ }^{3} \mathrm{He}$-to-tritiun converter.

b Average; assuming that $85 \%$ of the neutrons have the energy multiplicat Ion given in Table 6 , while $15 \%$ of the neutrons have an energy wultiplication of 1.5 and 4.38 for, respectively, D-T and D-D neutrons (see Ref. 23).

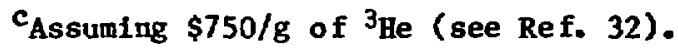

Another Indication on the signiflcance of the ${ }^{3}$ He inventory needs of TCD reactors can be obtained by considering the tritium inventory and tine required for providing the ${ }^{3}$ He inventory. With a tritiun half-1ife of 12.23 $\mathrm{yr}$, the accumulation of $17.6 \mathrm{~kg}$ of ${ }^{3} \mathrm{he}$ requires about $310 \mathrm{~kg}$ tritiun-years. The tritium inventory of a typical $D-T$ fusion power reactor is expected to be of the order of $10 \mathrm{~kg}$. Thus, the amount of ${ }^{3} \mathrm{He}$ accumulated in $30 \mathrm{yr}$ from tritium decay in such a reactor is the ${ }^{3}$ He inventory needs of a full-size TCD reactor. 
Still another Indicator of the ${ }^{3} \mathrm{He}$ inventory needs of a TCD reactor is the length of time of operation of the TCD reactor required for accumulating the ${ }^{3}$ He inventory needed. The Idea is to begin operating the reactor in the SCD mode of operation (possibly assisted by additional external plasma heating) until enough ${ }^{3} \mathrm{He}$ from the $D(D, n)^{3}$ He is accumulated. For a thermal first wall loading constraint of $1 \mathrm{MW} / \mathrm{m}^{2}$ assumed, it is estiuated that a total of 54 days of operation are required for accumulating all the ${ }^{3} \mathrm{He}$ inventory needed for the TCD reactor using the $P C A: \mathrm{H}_{2} \mathrm{O}=10: 85$ blanket.

${ }^{3}$ He inventory needs even lower than Identifled above could be concelved by using beryllium as a major blanket constituent. As the beryllium can pro$v i d e, v i a n, 2 n$ reactions, more than one extra neutron per $D-T$ neutron, the ${ }^{3}$ He inventory needed for the TCD mode of operation might be only about one-half its value without the beryllium neutron multiplier.

The interest in minimal ${ }^{3} \mathrm{He}$ inventory illustrated above does not imply that minimal. 3He inventory should be the design goal for a TCD reactor. In the PCA: $\mathrm{H}_{2} \mathrm{O}:{ }^{3} \mathrm{He}$ blankets considered, minimal ${ }^{3} \mathrm{He}$ inventory Implies relatively low PCA volume fraction. A low PCA volume fraction inplies relatively low blanket energy multiplication and relatively poor shielding properties. Thus, there exists an economic tradeoff between a low $3_{\text {ine }}$ inventory and a high blanket energy multiplication. Consequently, an overall system optinization Is required for Identifying the most desirable blanket perfornance (measured in terms of the ${ }^{3} \mathrm{He}$ inventory and energy multiplication). Such an optinization is beyond the scope of this work.

\section{REACTOR DESTGI}

\subsection{Strategs and Assuptions}

The plasma and machine characteristics of the TCD tokanaks are calculated using the assumptions and models developed by ANL, as embodied in the TRAC-II code [23]. It uses the sane general procedurc applied to the design of both the STARFIRE D-T [27] and the WILDCAT Cat-D [4] reactors. The specific strategy adopted for the present study follows closely that used in the recent ANL study of tritiun-lean plasmas. Table 7 brings a brief sumary of the assumptions used. In the rest of this section we shall describe the difference in the strategy and assumptions used for this study relative to those used in Ref. 23. 
TABLE 7

A Summary of Assuaptions Used for TRAC-II Calculations

- Total thermal power (MW)

4000

- First wall thermal loading (MW/ $\left.{ }^{2}\right)$

$\mathbf{l}$

- $\bar{B}_{T}(a)(x)$

10

- Maximum toroidal fleld strength (Tesla)

14.3

- Aspect ratio, A (m)

3.25

- Elongation, $\kappa$

1.6

- D-shapedness, a

0.2

- Safety factor

$q(a)$

3.0

$q(0)$

1.0

- Plasma rmperature and density

Profiled

- Particle/ent... conflnenent time ratio

0.25

- Ion/energy confinement time ratio

4.0

- Current drive

REB

- Beryllium impurity level (z)

0

- Cyclotron radiation reflection coefficient $0.9^{b}$

- Blanket thickness (Inboard/outboard) (cm) 30/70

- Shield thickness (inbogrd/outboard) (cn) 61/150

- Blanket energy multiplication (D-T/D-D neutrons) $1.50 / 1.76$

as long as $B_{T_{\max }} \leq 14.3 \mathrm{~T}$; otherwise $\vec{\beta}_{T}$ is adjusted to give right plasma densit $\frac{\text { max }}{\text { with }} B_{\mathrm{T}_{\text {nax }}}=14.3 \mathrm{~T}$.

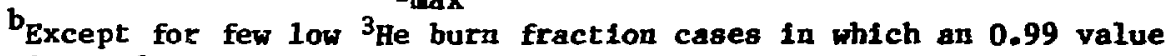
Is used. 
In the course of the TRAC-II salculations, the magnetic field strength is allowed to exceed 14.3 Tesla -- supposed1 the upper practical 1imit expected [23] - Whenever TRAC-II calls for field strengths exceeding $14.3 \mathrm{Tesla}$, we assume that the machine is designed to have 14.3-T magnets, while adjusting $B$ so as to preserve the plaswa density. Even though there are indications that tokamak reactors might be designed with $\bar{B}_{T}$ values sfignificantly higher than 10\% [34], we suggest that the higher the $\beta$ (actually, the higher the $\vec{\beta}_{T}{ }^{B} T_{\max }$ ) value called for by TRAC-II calculations, the more doubtful is the practical realization of this design.

The plasma is assumed, In this study, to have no impurities (except for ash), so as to enable ignition even when only a small fraction of the ${ }^{3} \mathrm{He}$ from the $D(D, n)^{3}$ He reaction fuses. Behind this assumption is the realization that the particle and energy confinement ability of large high field tokamaks (or the 11ke) machines is not known at present well enough to preclude the possibility that such machines may be designed to have a better energy balance than presently perceived. Otherwise, these reactors will have to be supplemented wth external heating. Guided by the same rationale, the cyclotron radiation reflection coefficient was increased from the 0.9 value used for most of the cases (as in Ref. 23) to 0.99 for only a few of the very low ${ }^{3}$ He burn-fraction cases.

Whereas the primary variable of the $E-G-J$ parametric study [23] was $r_{T} \equiv$ $\bar{n}_{\mathrm{T}} / \overline{\mathrm{n}}_{\mathrm{D}}$ (varied in between $4.8 \times 10^{-3}$ for Cat-D, to $\sim 1.0$ for $D-T$ ), the primary variable used for the present study is $\alpha \equiv$ the fraction of the ${ }^{3}$ He which fuses In the plasma. (In the E-G-J study, $\alpha$ was very close to efther 1.0 or 0.0 ). As $\alpha$ is not a free input parameter for TRAC-II, it was varied by adjusting the parameter $R_{3} \equiv$ fraction of ${ }^{3}$ He atoms reaching the first wall, which is reflected back to the plasma. This adjustnent is done paranetrically, so as to bracket the desirable value of $\alpha$, to allow interpolating the results to the specific $\alpha$ of interest.

As 1s, the TRAC-II code was not set to define TCD plasnas, $1 . e .$, to adjust the rate of tritiun supply from external (to the plasna) sources so as to assure the TCD mode of operation. To arrive at the TCD node of operation, $\mathbf{r}_{\mathbf{T}}$ is varled paranetrically to cover the range around $f=1$, where 


$$
f \equiv \frac{\bar{\pi}_{D} \bar{n}_{T}\langle\sigma v\rangle_{D-T}-(1 / 2) \vec{x}_{D}^{2}\langle\sigma v\rangle_{D-D}}{\alpha(1 / 2) q_{D}^{2}\langle\sigma v\rangle_{D-D}} .
$$

The performance characteristics pertaining to $f=1$ 1s then obtained by interpolating TRAC-II results pertaining to the neighboring $f$ values.

Losses of ${ }^{3} \mathrm{He}$ and trittum (due to leakage, nomper fect recovery and radioactive decay) are neglected. These losses are, however, expected to be snall, and they could be compensated for by adding to the blanket some ${ }^{3} \mathrm{He}$ from external (to the reactor) sources.

The Inboard shield thickness is kept flxed, rather than adjusted with the neutron source characteristic of each specific design (as done in Ref. 23). To appreclate the Implications of this approximation, the sensitivity of the TCD reactor performance parameters to this shield thickness is established (In Sec. 3.6).

A similar approach is adopted with regard to the blanket energy nuitiplication. A design independent value $\left(1.50\right.$ and $1.76^{\mathrm{C}}$ for, respectively, the 14-MeV and $2.45 \mathrm{MeV}$ ueutrons) is used. The sensitivity of the reactor performance characteristics to the blanket energy nultiplication is then established. The couple of approximations described above enabled proceeding with the reactor studies (using TRAC-II) before having results from detailed neutronfc studies - a must strategy for the short duration of the present study.

From the above assumptions and approximations it is apparent that the present assessment gives the TCD mode of operation the nerit of doubt. If found to be significantly more promising than other D-D based modes of operation, it might be fustified to enbark upon a nore thorough assessnent; otherwise, the TCD mode of operation is not likely to be of much practical interest for fusion power reactors.

\footnotetext{
$c_{\text {The }} \varepsilon_{D-D}$ was adjusted artificially to account for all the difference in the blanket. energy multiplication between a Cat-D and a TCD blanket.
} 
The costing of the TCD (and other) tokanaks exanined, the economic analysis methodology and assumptions are adopted as are from Ref. 23. All the cost figures quoted are given in 1980 dollars. Future studies wi1l require care ful assessment of the cost items lacluded in TRAC-II, and their scaling laws for TCD reactors.

\subsection{Reference Reactors and Effects of Impurities}

Three reactor designs from the E-G-J study [23] were adopted as references against which the TCD reactors are to be compared. These are the:

- D-T reactor: Case No. 1 of Ref. 23, representing STARFIRE [27].

- Cat-D reactor: Case No. 9 of Ref. 23, representing wILDCAT [4].

- Cat-D-T reactor: Case No. 8 of Ref. 23.

The latter is the T-lean tokamak design the tritium breeding of which is closest to that required for the TCD mode of operation.

Table 8 summarizes wajor design and performance parameters of the three reference reactors calculated using the ground rules described in Sec. 3.1 excluding the impurity level -- a 3\% beryllium concentration is assumed to be presented in the plasmas of Table 8. The parameters presented in Table 8 are identical with those of Ref. 23. Table 9 brings the design and performance parameters for the same reactors, the plasma of which is free of impurities. Being impurity-free as well, the perforwance of the TCD reactors under consideration is to be compared with that of Table 9.

Comparing Table 9 with Table 8 it is observed that impurfties have but a very small effect on D-T plasmas. D-D based plasmas (represented by the Cat-D plasma), characterized by a higher tenperature, are nore sensitive to the Impurity level, particularly sensitive is the nt requirement for igition without impurities $n \tau$ drops to about one-half their nominal value. Along with $n \tau$, there is a reduction in the ash concentration and a slight reduction in the magnetic field strength required to provide a given power output. Due to the first wall thermal loading and total thermal power constraints, however, there is only a negligible change in the size of the machines. Consequently, impurity renoval has but a very snall cost saving effect; it is due, primarily, to the lower magnetic field requirements. 
TABLE 8

Selected Design and Perfornance Paraneters of the Re ference ${ }^{*} D-T, C a t-D-T$, and Cat-D Tokanaks

\begin{tabular}{|c|c|c|c|}
\hline \multirow[b]{2}{*}{ Parameter } & \multicolumn{3}{|c|}{ Reactor Type } \\
\hline & $\mathbf{D}-\mathbf{T}$ & Cat-D-T & Cat-D \\
\hline Major radius (m) & 6.10 & 9.32 & 10.59 \\
\hline Peak toroidal field (T) & 8.31 & 13.6 & 13.34 \\
\hline Field in plasma (T) & 4.16 & 7.81 & 7.93 \\
\hline Plasma toroidal average $\beta(x)$ & 10.0 & 10.0 & 10.0 \\
\hline Plasma current (MA) & 10.5 & 30.2 & 34.9 \\
\hline Confinement parameter, $n_{D} \tau_{E}\left(m^{-3} s\right)$ & $8.64+19$ & $2.19+21$ & $2.71+21$ \\
\hline Average electron temperature (kev) & 7.0 & 21.9 & 24.0 \\
\hline Average Ion temperature (keV) & 7.12 & 22.6 & 24.7 \\
\hline Fraction of ${ }^{3} \mathrm{He}$ fused & $\mathbf{0}$ & 1.0 & 1.0 \\
\hline Tritium breeding ratio ${ }^{a}$ & 0.994 & 0.404 & 0.0027 \\
\hline Deuteron density $\left(\mathrm{m}^{-3}\right)$ & $1.20+20$ & $2.11+20$ & $2.00+20$ \\
\hline$\overline{\mathbf{n}}_{\mathrm{T}} / \overline{\mathbf{n}}_{\mathrm{D}}$ & 1.00 & 0.01 & 0.0042 \\
\hline$\overline{\mathrm{n}}_{3} \mathrm{He} / \overline{\mathrm{n}}_{\mathrm{D}}$ & $3.04-5$ & 0.138 & 0.125 \\
\hline $\bar{n}_{p} / \bar{n}_{D}$ & $6.98-5$ & $2.94-2$ & $4.13-2$ \\
\hline$\overline{\mathbf{z}}_{\alpha} / \overline{\mathbf{n}}_{\mathrm{D}}$ & $1.04-2$ & $1.97-2$ & $1.66-2$ \\
\hline Fusion power ${ }^{b}(M W)$ & 3225 & 3034 & 2949 \\
\hline Charged particles power (MW) & 647 & 1460 & 1870 \\
\hline Net electric power (MW) & 1335 & 1321 & 1317 \\
\hline First wall loading $\left(M H / \mathrm{m}^{2}\right)$ & & & \\
\hline $\mathrm{D}-\mathrm{T}$ neutrons & 3.98 & 1.00 & 0.48 \\
\hline D-D neutrons & - & 0.081 & 0.095 \\
\hline Total capital cost ${ }^{c}(M \$)$ & 1973 & 3243 & 3832 \\
\hline Cost of capacity $(\$ / \mathrm{kWe})$ & 1478 & 2454 & 2910 \\
\hline Component replacement cost $(\mathrm{M} \$ / \mathrm{yr})$ & 21.5 & 5.83 & 5.18 \\
\hline Cost of electricity (mflls/kih) & 27.2 & 40.3 & 47.2 \\
\hline
\end{tabular}

${ }^{*}$ See Ref. 23.

a Number of tritons produced in the blanket per average fugion neutron.

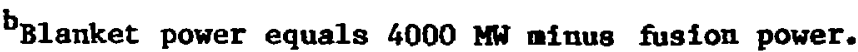

cIncluding indirect, but no escalation during construction costs.

Expressed in 1980 dollars. 


\section{TABLE 9}

Selected Design and Performance Parameters of the Reference $D-T$, Cat-D-T, and Cat-D Tokamaks without Impurities

\begin{tabular}{|c|c|c|c|}
\hline \multirow[b]{2}{*}{ Parameter } & \multicolumn{3}{|c|}{ Reactor Type } \\
\hline & $\mathbf{D}-\mathbf{T}$ & Cat-D-T & Cat-D \\
\hline Major radius (m) & 6.10 & 9.31 & 10.57 \\
\hline Peak toroldal fleld $(\mathrm{T})$ & 8.18 & 13.14 & 12.87 \\
\hline Field in plasma ( $T$ ) & 4.10 & 7.55 & 7.64 \\
\hline Plasma toroidal average $B(\%)$ & 10.0 & 10.0 & 10.0 \\
\hline Plasma current (MA) & 10.4 & 29.2 & 33.5 \\
\hline Confinement parameter, $n_{D} \tau_{E}\left(m^{-3} s\right)$ & $7.98+19$ & $1.28+21$ & $1.46+21$ \\
\hline Average electron temperature (kev) & 7.0 & 21.9 & 24.0 \\
\hline Average Ion temperature (keV) & 7.1 & 22.6 & 24.7 \\
\hline Fraction of ${ }^{3} \mathrm{He}$ fused & 0 & 1.0 & 1.0 \\
\hline Tritium breeding ratio ${ }^{a}$ & 0.994 & 0.406 & 0.011 \\
\hline Deuteron density $\left(m^{-3}\right)$ & $1.20+20$ & $2.11+20$ & $2.00+20$ \\
\hline $\overrightarrow{\mathrm{n}}_{\mathrm{T}} / \overline{\mathrm{n}}_{\mathrm{D}}$ & 1.00 & 0.01 & 0.0042 \\
\hline$\overline{\mathrm{n}}_{3} \mathrm{He} / \overline{\mathrm{n}}_{\mathrm{D}}$ & $2.79-5$ & 0.137 & 0.125 \\
\hline$\overline{\mathrm{n}}_{\mathrm{p}} / \overline{\mathrm{n}}_{\mathrm{D}}$ & $6.43-5$ & $1.71-2$ & $2.23-2$ \\
\hline$\overline{\mathrm{n}}_{\alpha} / \overline{\mathrm{n}}_{\mathrm{D}}$ & $9.53-3$ & $1.15-2$ & $9.02-3$ \\
\hline Fusion power ${ }^{b}(M W)$ & 3225 & 3034 & 2949 \\
\hline Charged perticles power (MW) & 647 & $1.46+3$ & $1.86+3$ \\
\hline Net electric power (MW) & 1335 & 1323 & 1319 \\
\hline First wall loading $\left(\mathrm{MW} / \mathrm{m}^{2}\right)$ & & & \\
\hline $\mathrm{D}-\mathrm{T}$ neutrons & 3.98 & 1.00 & 0.487 \\
\hline D-D neutrons & $2.04-3$ & $8.09-2$ & $9.48-2$ \\
\hline Total capital cost ${ }^{c}(M \$)$ & 1967 & 3189 & 3755 \\
\hline Cost of capacity $(\$ / k W e)$ & 1473 & 2411 & 2847 \\
\hline Component replacement cost (MS/yr) & 21.53 & 5.84 & 5.19 \\
\hline Cost of electricity (mills/kWh) & 27.1 & 39.7 & 46.2 \\
\hline
\end{tabular}

* See Ref, 23.

a Number of tritons produced in the blanket per average fusion neutron.

${ }^{b}$ Blanket power equals $4000 \mathrm{MW}$ minus fusion power.

'Including indirect, but no escallation during construction costs.

Expressed in 1980 dollars. 


\subsection{Ef fect of Partial Burn of ${ }^{3}$ Ee}

Consider, next, the Cat-D-T reactor (reference case No. 8 [23]) in which the ${ }^{3} \mathrm{He}$ is not required to fuse completely; Figs. 10 and 11 show the variation of selected reactor parameters with a -- the fraction of ${ }^{3} \mathrm{He}$ which escapes fusion. The TBR and $n \tau$ for the reactors considered are being maintained at a constant value (of Case No. 8) -- TBR $\approx 0.4$ and $\mathrm{nt}=2.2 \times 10^{21} \mathrm{~m}^{-3} \mathrm{~s}$. The TBR is defined here, after Ref. 23, as the net number of tritons burned In the plasma divided by the total number of neutrons (1ncluding both D-T and D-D neutrons) produced in the plasma; in a loss-free system this TBR is related to the blanket $\gamma^{\prime}$ 's as follows:

$$
\mathrm{TBR}=\alpha /(1+N)-\left(\gamma_{D-D}+N_{D-T}\right) /(1+N)
$$

The TBR is kept constant for this serles of runs regardless of the value of $\alpha$.

It Is observed that as the fraction of the ${ }^{3}$ He saved (1.e., not fused) increases, the size of the plasma (measured by $R$ ) decreases. This is due to the lower fraction of fuston energy release in the form of charged fusion products, enabling a design of a more compact reactor without exceeding the first wall thermal loading constraint of $1 \mathrm{~mW} / \mathrm{m}^{2}$. The deuterium density needs to increase with $\alpha$, to assure the total power output constraint of $4000 \mathrm{MW}(\mathrm{t})$. Consequently, the power density, as well as the neutron wall loading significantly increase with $\alpha$ (Fig. 11). For this to happen, though, the magnetic fleld (and /or $B$ ) needs to be significantiy increased as well.

Figure 12 shows the $\alpha$ dependence of the total capital cost and of the cost of electricity (COE). It is observed that the capital cost of the reactor decreases appreclably as the fraction of the ${ }^{3}$ He atoms saved is increased. This is due, primarily, to the reduced size of the fusion device with the increase in $\alpha$. As the total capital cost is the dominant contributor to the COE, the COE shows a similar a dependence.

It Is concluded that, subjected to the ground rules and assumptions used, it pays to save as much of the ${ }^{3} \mathrm{He}$ as possible. The ${ }^{3} \mathrm{He}$ fraction which could be saved is limited, In reality, by the ignition requirement (discussed in Sec. 3.1) and confinement requirement (which affects the $D-3$ He fusion probability before the ${ }^{3} \mathrm{He}$ leaks out of the plasma [35]). For the tokamak reactors considered above, the maximal attainable $\alpha$ is sstimated to be $\sim 0.8$. The $\mathrm{COE}$ 


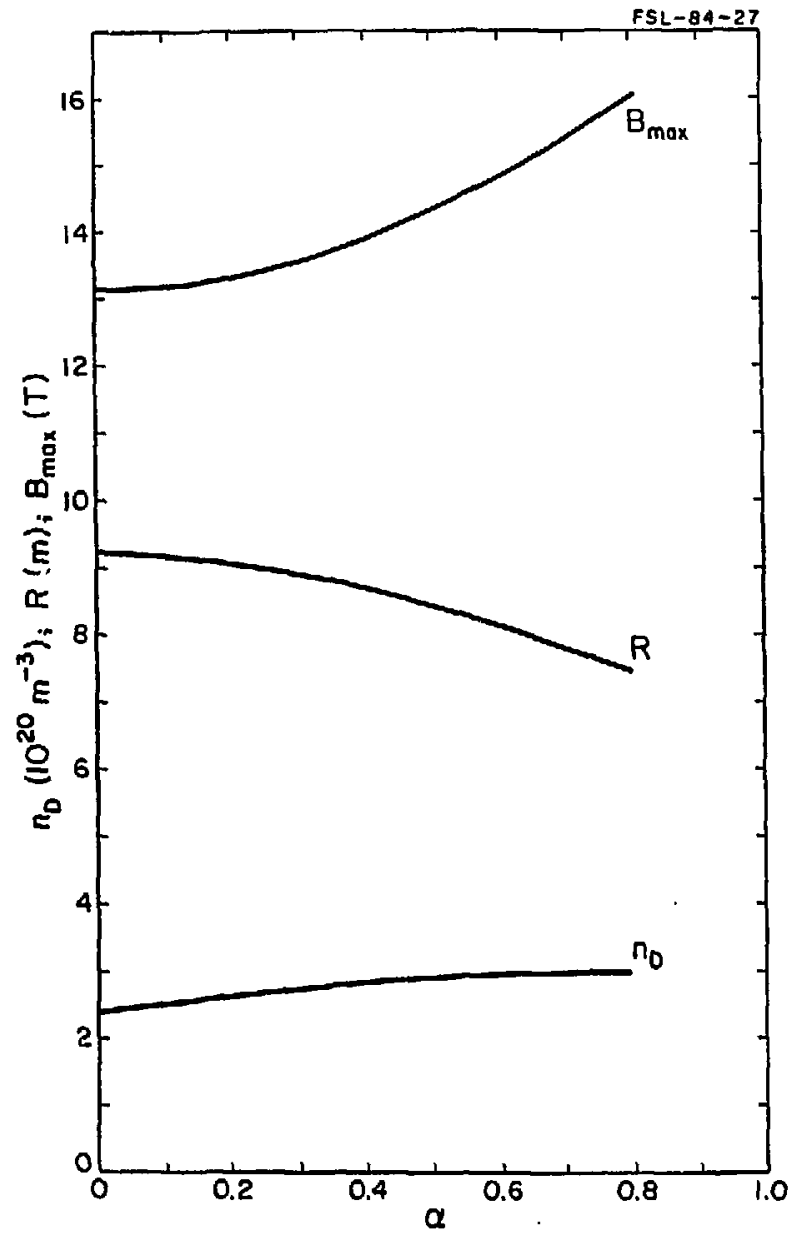

F1g. 10. Ef fect of the fraction of ${ }^{3} \mathrm{He}$ escaping fusion $(\alpha)$ on the deuteron density $\left(n_{\mathrm{D}}\right)$, major radius ( $R$ ) and maximal magnetic field strength ( $B_{\text {max }}$ ) of TBR $=0.4$ tokamaks.

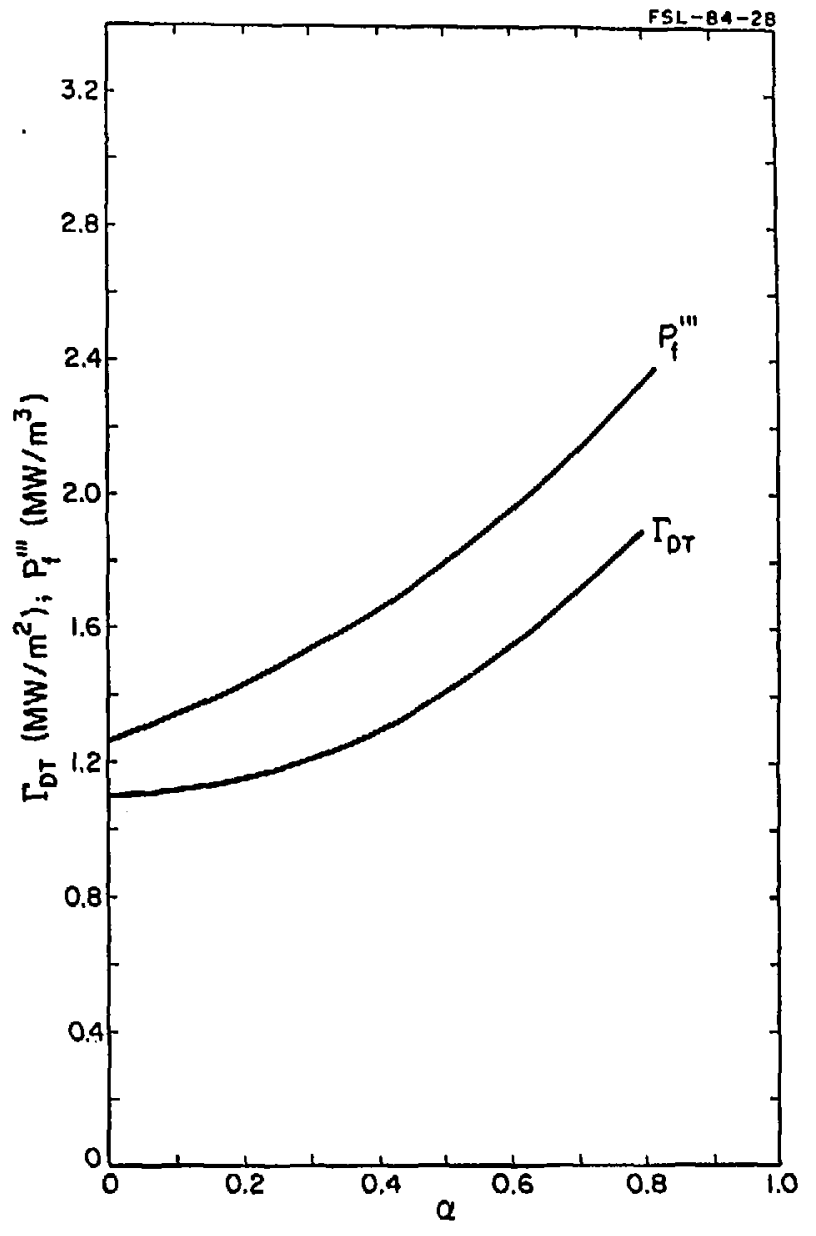

Fig. 11. Effect of the fraction of ${ }^{3}$ He escapling fusion $(\alpha)$ on the $D-T$ neutron first wall loading $\left(\Gamma_{D-T}\right)$ and fusion power density $\left(\rho_{\mathrm{f}}-{ }^{-}\right)$of $\mathrm{TBR}=0.4$ tokamaks. 


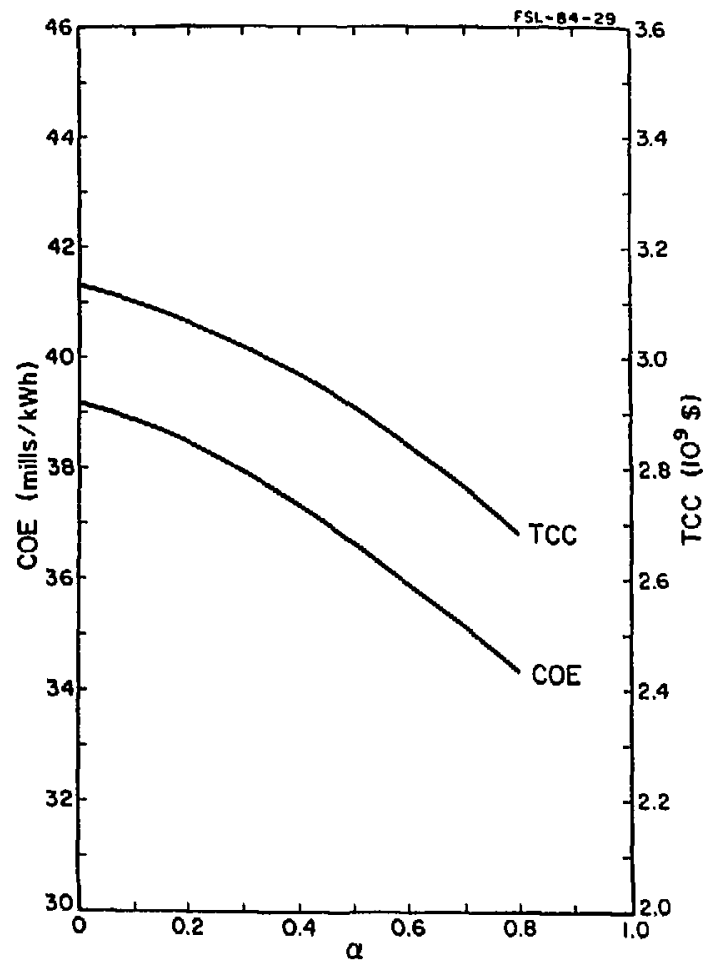

F1g. 12. Effect of the fraction of ${ }^{3}$ He escaping fusion $(\alpha)$ on the total capital cost (TCC) and cost of electricity (COE) of $T B R=0.4$ tokamaks.

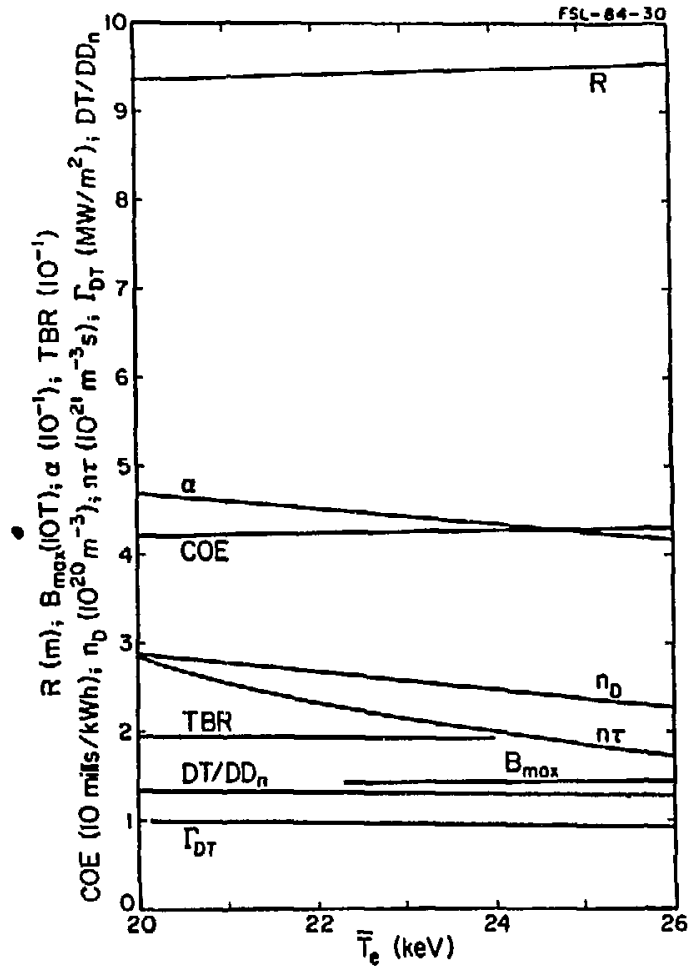

Fig. 13. Selected charcteristics of TCD tokamaks, including major radius (R); maximal magnet $1 \mathrm{c}$ fleld for $\bar{\beta}=10 \%$ ( $B_{\text {max }}$ ); fraction of ${ }^{3} \mathrm{He}$ escaping fusion ( $\alpha$ ); tritium breeding ratio (TBR); cost of electricity (COE); deuterons density ( $\mathrm{nD}_{\mathrm{D}}$ ); confinement parameter ( $\mathrm{n \tau}$ ); $D-T$ neutrons first wall loading $\left(T_{D-T}\right)$; ratio of $D-T$ to $D-D$ neutrons $\left(D-T / D^{-} \bar{D}_{n}^{T}\right.$ ); and average electron temperature $\left(\bar{T}_{e}\right) \cdot{ }^{3} \mathrm{He}$ recycling coefficient $R_{3}=0.99$. 
of the $\alpha=0.8$ tokamak is found (Fig. 12) to be $87 \%$ of the COE of the reference ( $\alpha=0$; 1.e., Case No. 8 of Ref. 23) tokamak.

\subsection{The TCD Kode of Operation}

Next, let us remove the $T B R=0.4$ and $n \tau=2.2 \times 10^{21} \mathrm{~m}^{-3} \mathrm{~s}$ constraints considered in the preceding section. The TBR Is adjusted to give the TCD mode of operation, so that the number of tritons supplied to the plasma [from sources other than the $D(D, p) T$ reaction] equals the number of ${ }^{3}$ He atoms which leaves the plasma.

Figures 13 through 15 sumarize part of the results of the parametric study carried out. Shown in each figure is the temperature dependence of selected parameters for certain ranges of $\alpha$. Practically, the range of $\alpha$ is determined by the recycling coefficlents $\left(R_{3}\right)-$ the probability of an ion which diffuses out of the plasma to be recycled back to the plasma due to interaction with the first wall. To reach ignition in the $\alpha \approx 0.9$ range (corresponding to the $R_{3}=0.75$ case), the cyclotron raidation coefficient was raised arbitrarily to $R_{\text {cycl }}=0.99$ (vs. $R_{c y c l}=0.90$ used as the reference). Consequently, the attainment of the high- $\alpha$ TCD cperating regime should be viewed as less probable than of $10 w-\alpha$ operation; it pends the attainment of an energy balance which is more favorable than that predicted by the model used in TRAC-II [23].

The $C O E$ is seen to be lower; the lower is the plasma temperature. This reflects, primarily, the reduction in the machine size (R) with the decrease in the plasma temperature, which is due to the increase in $\alpha$ as the temperature decreases. The latter is a consequence of the decrease in the $\left\langle\mathrm{D},{ }^{3} \mathrm{He}\right\rangle /$ $\langle D, D\rangle_{3 \mathrm{He}}$ reactivity ratio with the decrease in the plasma temperature. The lower the plasma temperature, however, the higher is the nt requirement for Ignition. Thus, economically it pays to design the TCD reactors to operate at the lowest temperature which permits ignition. This observation is in agreement with the conclusions reached in Ref. 23 on tritfum-1ean reactors.

The $\alpha$ dependence of selected characteristics of the TCD reactors examined In the parametric study is summarlzed in $\mathrm{Fig}$. 16. The results are presented for equal $n \tau$ values of $2.4 \times 10^{21}$ and $3.0 \times 10^{21} \mathrm{~m}^{-3}-6$. Except for the plasma temperature, all the other parameters shown are, essentially, nt Independent. It ts observed that the higher $\alpha$, the lower is the COE. Thus, economically it 


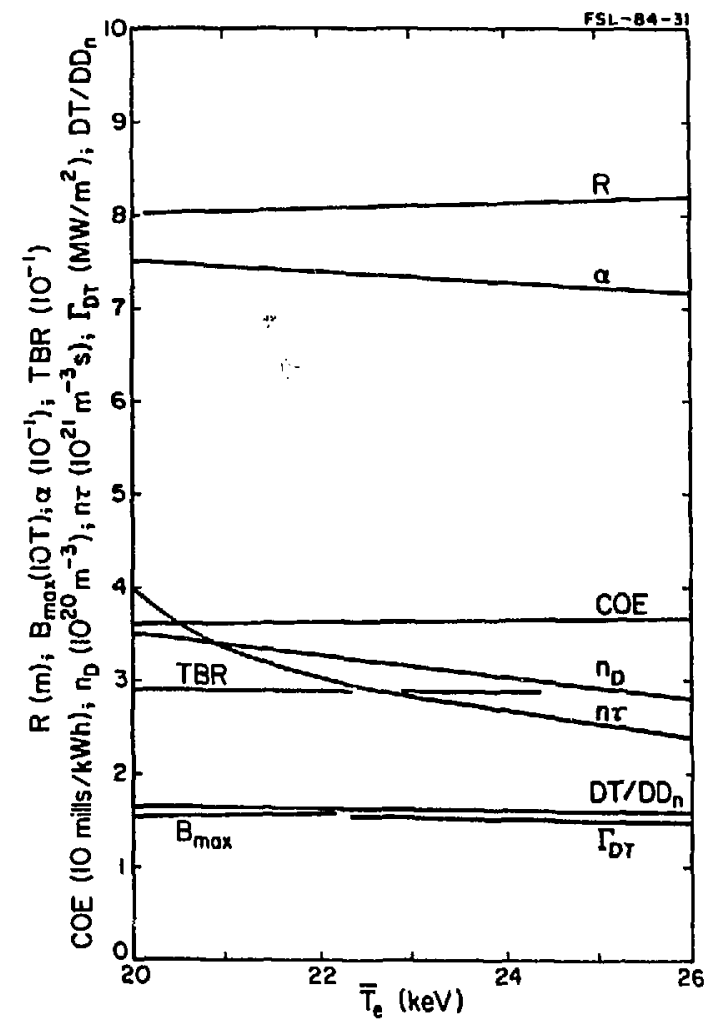

Fig. 14. Selected characteristics of TCD tokamaks, including major radius (R); maximal magnetic field for $\bar{\beta}=10 \%$ ( $B_{\max }$ ); fraction of ${ }^{3}$ He escaping fusion ( $\alpha$ ); tritium breeding ratio (TBR); cost of electricity (COE); deuterons density ( $\left.n_{D}\right)$; confinement parameter (nT); ratio of $D-T$ to $D-D$ neutrons $\left(D-T / D-D_{n}\right)$; and average electron temperature $\left(\bar{T}_{e}\right) \cdot{ }^{3} \mathrm{He}$ recycling coefficient $R_{3}=0.95$ ).

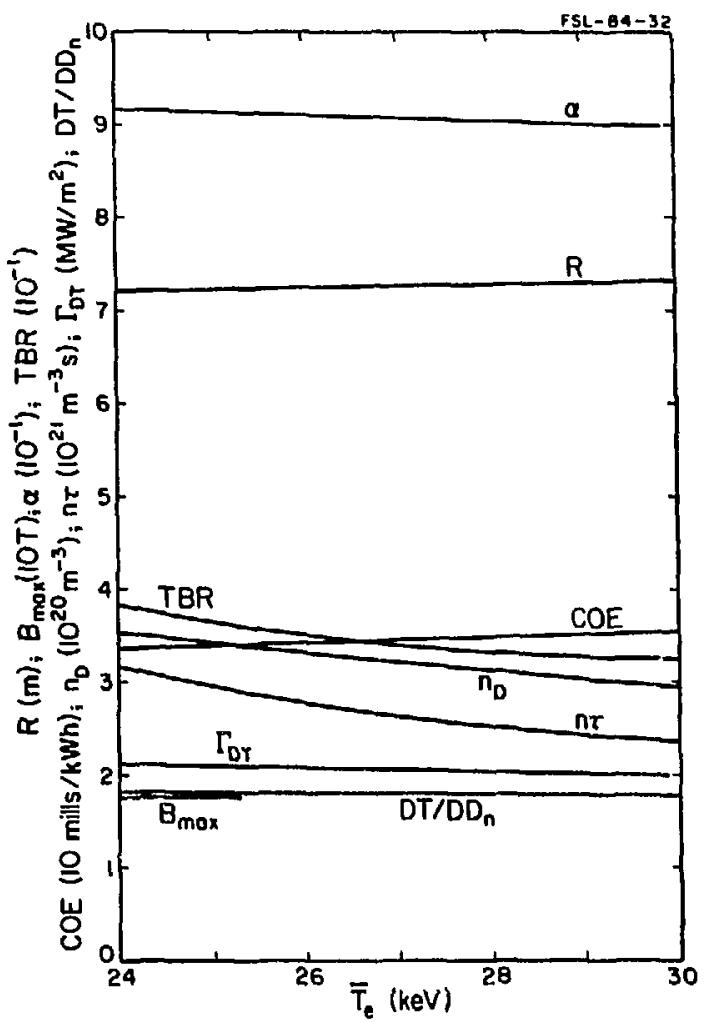

Fig. 15. Selected characteristics of TCD tokamaks, including major radius (R); maximal magnetic fleld for $\vec{B}=10 \%$ ( $B_{\max }$ ); fraction of ${ }^{3} \mathrm{He}$ escaping fusion ( $\alpha$ ); tritium breeding ratio (TBR); cost of electricity (COE); deuterons density $\left(n_{D}\right)$; conf 1 nement parameter ( $\left.n \tau\right)$; $D-T$ neutrons first wall loading $\left(\Gamma_{D-T}\right)$; ratio of $D-T$ to $D-D$ neutrons $D-T / D-D_{n}$; and average election temperature $\left(\bar{T}_{e}\right) \cdot{ }^{3}$ He recycling coefficient $R_{3}=0.75$. 


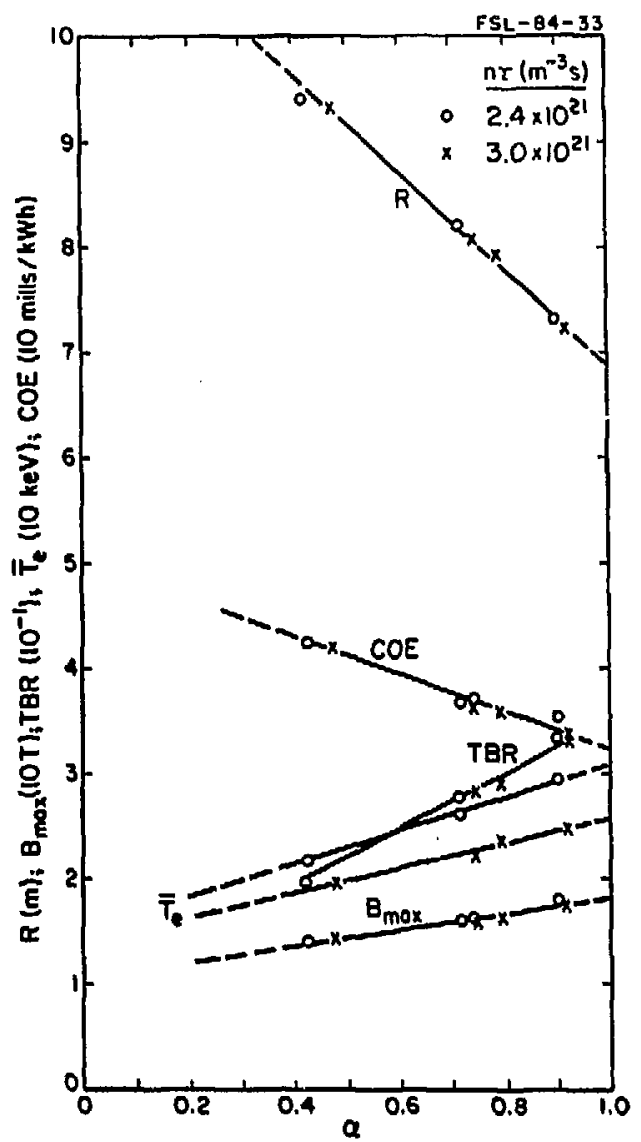

F1g. 16. Effect of fraction ( $\alpha$ ) of ${ }^{3}$ He escaping fusion on the major radiun (R); maximal magnet ic field for $\bar{\beta}=10 \%$ ( $B_{\text {max }}$ ); tritium breeding ratlo (TBR), average plasma electron temperature $\left(\mathrm{T}_{e}\right)$; and cost of electricity (COE) of TCD tokamak reactors with nt of $2.4 \times 10^{21}$ or $3.0 \times 10^{21} \mathrm{~m}^{-3} \mathrm{~s}$.

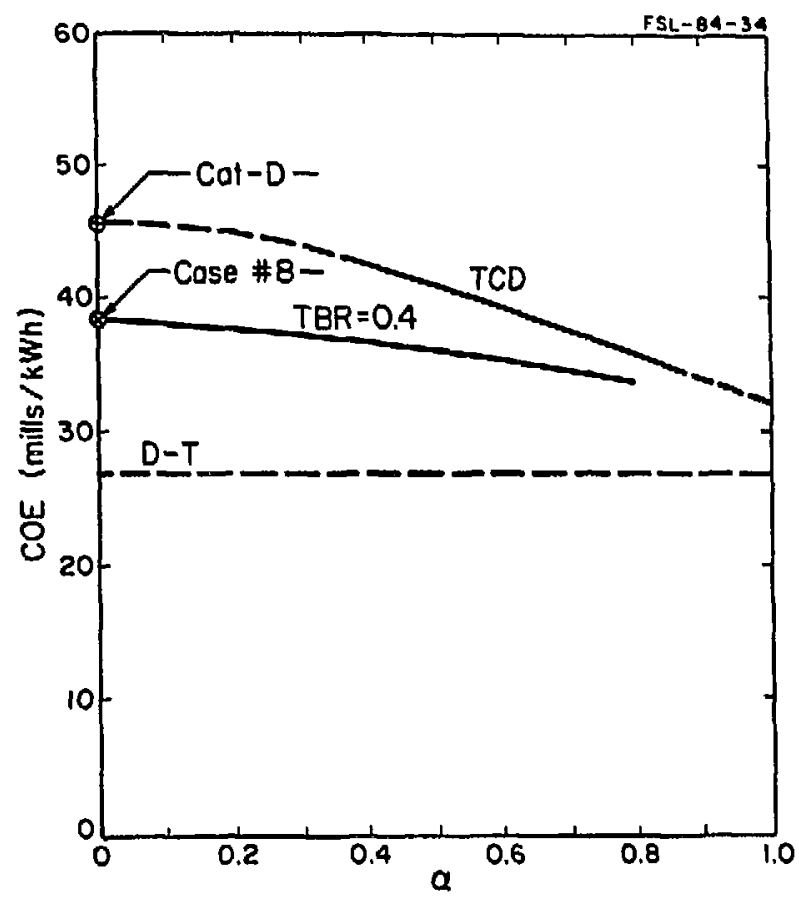

F18. 17. Comparison of cost of electricity (COE) of TCD, Cat $-D, D-T$, and $T B R=$ 0.4 tokamaks. 
1s desirable to design the reactor to convert as much of the ${ }^{3}$ He into tritiun as possible. Constraining the maxinal a value attainable in practice will be the plasma energy loss rate (to be affected largely by the plasma impurity level and radiation reflection coefficient) and the naxinal magnetic field strength (actually, $\mathrm{BB}_{\mathrm{T}_{\max }}^{2}$ ) attainable. Table 10 shows selected characteristics of two point designs of TCD reactors.

\subsection{The Tritiu-Assisted TCD Hode of Operation}

Figure 17 compares the COE of the TCD reactors (Sec. 3.4) and of the TBR $=0.4$ (1.e., Case No. 8 11ke [23]; Sec. 3.3) reactors as a function of the fraction of ${ }^{3}$ He leaving the plasma ( $\alpha$ ). Also shown in Fig. 17 is the CoE of the reference $D-T$, Cat-D and Case No. 8 reactors of Ref. 23.

The reduced $\mathrm{COE}$ of the $\mathrm{TCD}$ and $\mathrm{TBR}=0.4$ reactors with the increase in $\alpha$ was discussed in the preceding sections, In connection with F1gs. 12 and 16. Figure 17 shows that the COE of the TBR $=0.4$ reactors is lower than of the TCD reactors. The difference between the two modes of operation is in the amount of tritium fed to the plasma from "external" sources [1.e., from sources other than the $D(D, P) T$ reaction]. In the TCD mode of operation the rate of external tritiun supply equals the rate of ${ }^{3} \mathrm{He}$ recovery; the corresponding TBR $<0.4$ (see FIg. 16). Alternatively, it can be sald that the TBR= 0.4 designs considered pertaln to a $f>1$ mode of operation [see Eq. (9) for definition of $\mathrm{f}$ ].

It is possible to refer to the $f>1$ situation as the tritiu-assisted mode of operation, i.e., a mode of operation in which the plasua fuses more tritium than the sum of the tritium produced from the $D(D, p) T$ and from the conversion of the fraction $\alpha$ of the ${ }^{3}$ He produced in the plasma into tritiun. The extra tritium needed for a $f>1$ mode of operation can be obtalned by incorporating in the blanket sone lithium (1n addition to ${ }^{3} \mathrm{He}$ ). In fact, as far as the plasma performance is concerned, all the tritium needed for operating the plasma at a given TBR can be bred from 11thiun; the ${ }^{3}$ He could then be saved for other applications (such as for $\mathrm{D}^{3} \mathrm{He}$ fusion reactors [35]). Alternatively, the tritium needed for the tritium-assisted node of operation could be obtained from other fusion or fission reactors.

The degree of tritium assibtance corresponding to the TBR $=0.4$ reactors considered is shown in Fig. 18. Consider, for exanple, the $\alpha=0.6$ design 
TABEE 10

Selected Design and Performance Parameters of Representative TCD Reactors - No Inpurities

\begin{tabular}{|c|c|c|}
\hline Parameter & Case A & Case B \\
\hline Cyclotron radiation reflection coefficient & 0.99 & 0.90 \\
\hline$\alpha$ & 0.90 & 0.765 \\
\hline Major radius ( $(\pi)$ & 7.29 & 7.98 \\
\hline Peak toroldal fleld ${ }^{a}(T)$ & $17.8[14]$ & $1640[14]$ \\
\hline Fleld in plasma ${ }^{a}(T)$ & $9.62[7.6]$ & $8.98[7.7]$ \\
\hline Plasma toroidal average $\beta^{(a)}(z)$ & $10[16]$ & $10(14]$ \\
\hline Plasma current (MA) & 29.1 & 30.0 \\
\hline Confinement parameter, $n_{D} \tau_{E}\left(m^{-3}\right)$ & $2.52+21$ & $2.59+21$ \\
\hline Average electron temperature (kev) & 28 & 26 \\
\hline Average 1on temperature (kev) & 29.6 & 27.2 \\
\hline Tritium breeding ratio $b$ & 0.33 & 0.29 \\
\hline Deuteron density $\left(m^{-3}\right)$ & $3.11+20$ & $2.91+20$ \\
\hline$\overline{\mathbf{n}}_{\mathrm{T}} / \overline{\mathbf{n}}_{\mathrm{D}}$ & $1.00-2$ & $8.53-3$ \\
\hline$\overline{\mathbf{n}}_{3} \mathrm{He} / \overline{\mathbf{n}}_{\mathrm{D}}$ & $9.49-3$ & $2.63-2$ \\
\hline$\overline{\mathbf{n}}_{\mathrm{p}} / \overline{\mathbf{n}}_{\mathrm{D}}$ & $2.54-2$ & $2.67-2$ \\
\hline$\overline{\mathbf{n}}_{\alpha} / \overline{\mathbf{n}}_{\mathbf{D}}$ & $1.98-2$ & $1.81-2$ \\
\hline Fuston power ${ }^{c}(M W)$ & 2939 & 2996 \\
\hline $\begin{array}{l}\text { Charged particles power fraction }(z) \\
\text { flrst wall loading }\left(\mu W / \mathbf{n}^{2}\right)\end{array}$ & 31 & 36 \\
\hline $\begin{array}{l}\text { D-T neutrons } \\
\text { D-D neutrons }\end{array}$ & $\begin{array}{l}2.03 \\
0.197\end{array}$ & $\begin{array}{l}1.60 \\
0.170\end{array}$ \\
\hline Blanket power (MW) & 1061 & 1004 \\
\hline Rectrculated power (MWe) & 96 & 96 \\
\hline Net electrical power (MW) & 1321 & 1321 \\
\hline Total capital cost ${ }^{d}$ (M\$) & 2749 & 2902 \\
\hline Cost of capacity $(\$ / \mathrm{kWe})$ & 2082 & 2197 \\
\hline Cost of electricity (n1lls/kWh) & 35.0 & 36.6 \\
\hline
\end{tabular}

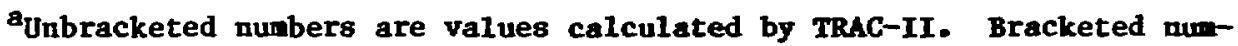
bers are examples for values the nachines nay be designed to have.

biumber of tritons produced in the blanket per average fusion neutron.

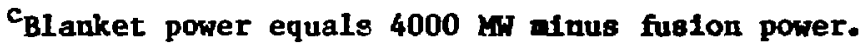

dIncluding indirect, but no escallation during conetruction costs. Expressed in 1980 dollars. 


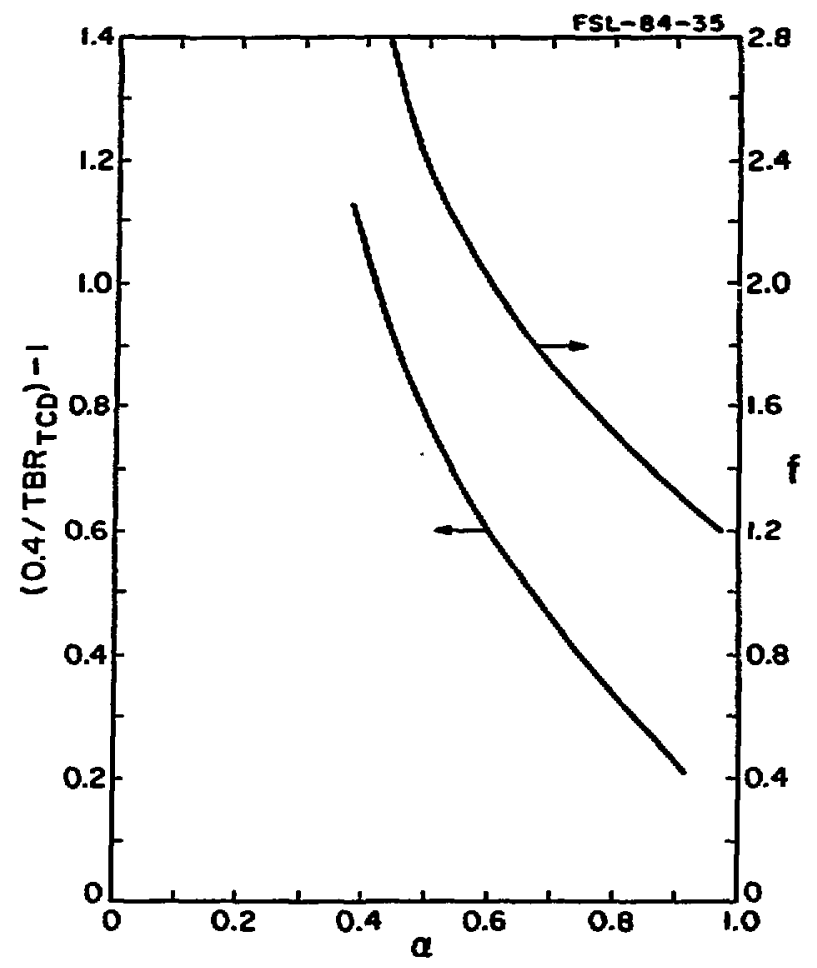

Fig. 18. Degree of tritium assistance for the $T B R=0.4$ reactors.

point. Its corresponding $f$ is $\sim 2$ implying that the number of tritons fed to the plasma from external sources is twice the number of ${ }^{3} \mathrm{He}$ atons saved. The TBR value for the corresponding TCD reactor t6 $0.25[1 . e .,(0.4 / \mathrm{TBR}-1)=$ $0.6]$.

In addition to offering a lower COE, tritium assistance improves the plasma energy balance, thus easing the ignition requirenents. This is due to the addition of fusion power deposited in the plasma originating fron the extra $D-T$ reactions. Thus, it may turn out that the tritium assistance will be called for to enable ignition of TCD plasmas, possibly compensating for the effects of impurities, relatively low cyclocron radiation reflection coefficient, etc. 


\subsection{Sengitioity Analyals}

\subsubsection{Introduction}

The sensitivity of the $D-T$ and Cat-D reactors to the plasma impurity level In D-T and Cat-D reactors was illustrated in Sec. 3.2. In the following we shall discuss the sensitivity of such reactors to the inboard blanket/ shield thickness, to the blanket energy multiplication, and to the first wall thermal loading. The reference Cat-D reactor will represent, in this sensitivity analysis, the $D-D$ based reactors.

The sensitivity analysis reported upon consists of limited variations of the design vartables and, except for one case, takes the Cat-D reactor to represent also $\mathrm{TCD}$ reactors.

\subsubsection{Effect of Blanket/Shield Thickness}

Table 11 illustrates the sensitivity of selected performance characteristIcs of the D-T and Cat-D reactors to the Inboard blanket/shield thickness, $\Delta_{\text {BS }}^{I}$. It is observed that in the tokamak designs considered, $\Delta_{B S}^{i}$ has no effect on the major radius of the machines. Its modest effect on the COE 1s due primarily to its effect on $B_{\max }$ - the larger $\Delta_{B S}^{i}$, the further is the TF coil from the plasma so the higher need be the magnetic field strength in the coil in order to maintain a given fleld strength in the plasma. The Cat-D reactor is more sensitive to $\Delta_{B S}^{i}$ than the $D-T$ reactor.

\section{TABLE 11}

Effect of Inboard Blanket/Shield Thtckness $\left(\Delta_{\mathrm{BS}}^{1}\right)$ on Selected Reactor Characterlstics*

\begin{tabular}{l|c|c|c|r}
\hline & \multicolumn{4}{|c}{ Reactor } \\
\cline { 2 - 5 } Characteristic & \multicolumn{3}{|c|}{ D-T } & \multicolumn{2}{c}{ Cat-D } \\
\hline$\Delta_{\mathrm{BS}}^{1}(\mathrm{~m})$ & $0.97^{\mathrm{a}}$ & 1.2 & $0.84^{\mathrm{a}}$ & 1.2 \\
$\mathrm{R}(\mathrm{m})$ & 6.1 & 6.1 & 10.6 & 10.6 \\
$\mathrm{~B}_{\max }(\mathrm{T})$ & 8.31 & 8.99 & 13.3 & 14.1 \\
$\mathrm{COE}(\mathrm{m} 111 \mathrm{~s} / \mathrm{kWh})$ & 27.2 & 27.5 & 47.2 & 49.5 \\
\hline
\end{tabular}

*Impurities included.

${ }^{a}$ Corresponding to the reference reactors design (Ref, 23). 
Using the first-wall neutron loading found for our typical TCD reactor and the neutron wall loading and $\Delta_{B S}^{i}$ values the nine reference reactors [23] were designed to have, it is found that the TCD reactor should have had a $\Delta_{B S}$ of $-0.93 \mathrm{~m}$ versus $0.91 \mathrm{~m}$ assumed at the outset. Using the results from the sensitivity analysis it is estimated that this difference in $\Delta_{\text {BS }}$ could pena11ze the TCD COE by about one-third of a percent only.

\subsubsection{Effect of Blanket Energy Multiplication}

Table 12 illustrates the sensitivity of the Cat-D reactor [23] to the blanket energy multiplication of the 14-MeV neutrons $\left(\varepsilon_{D-T}\right)$. The maln effect of Increasing $\varepsilon_{\mathrm{D}-\mathrm{T}}$ is a reduction in the fusion power level (for a given total power) and therefore in the size and cost of the reactor as well as in the COE.

TABLE 12

Effect of Blanket Energy Multiplication for $14-\mathrm{MeV}$ Neutrons $\left(\varepsilon_{D-T}\right)$ on Selected Characteristics of the Cat-D and TCD Reactors

\begin{tabular}{l|c|c|c|c}
\hline \multirow{2}{*}{ Characterist1c } & \multicolumn{4}{c}{ Reactor } \\
\cline { 2 - 5 }$\varepsilon_{D-T}$ & \multicolumn{3}{|c|}{ Cat-D } & \multicolumn{2}{c}{$T^{\mathrm{T}}$} \\
Fusion power (GW) & $1.5^{\mathrm{b}}$ & 1.8 & 1.5 & 1.9 \\
Heating powwer (MH & 2.95 & 2.76 & 3.03 & 2.6 \\
$\quad$ R (m) & - & - & 80. & 68. \\
\multicolumn{1}{c|}{$B_{\text {max }}(\mathrm{T})$} & 10.6 & 10.2 & 8.4 & 7.7 \\
Total capital cost (B\$) & 3.83 & 3.66 & 3.01 & 2.8 \\
COE (mills/kWh) & 47.2 & 45.2 & 41.4 & 38.1 \\
\hline
\end{tabular}

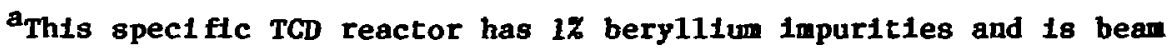
heated; its fusion energy gain is $Q * 37$. It has an $\alpha$ of 0.72 , corresponding to an $R_{3}$ of 0.95 . It appears that the version of TRAC-II used for the present study is not set to properly account for the effect of the beam heating (assumed to use compressional Al fven waves). The sensitivity of the TCD reactor paraneters to $\varepsilon_{\mathrm{D}-\mathrm{T}}$ is expected, nevertheless to be properly predicted.

${ }^{b}$ Corresponding to the reference Cat-D reactor (Ref. 23). 
The particular increase in $\varepsilon_{\mathrm{D}-\mathrm{T}}$ considered in Table 12 corresponds to the increase in the blanket energy multiplication of a TCD reactor with $\alpha=0.9$ in which Instead of the $90 \%$ of the plasma produced ${ }^{3} \mathrm{He}$ atoms to be converted Into tritium (in the blanket), ${ }^{6} \mathrm{LI}$ is used for the production of the same amount of tritium. The corresponding reduction in the $\operatorname{COE} 1 \mathrm{~s} \sim 4 \%$.

Also illustrated in Table 12 is the sensitivity of a beam-heated TCD reactor to the blanket energy multiplication. This reactor benefits fron increasing $\varepsilon_{D-T}$ slightly more than the Cat-D reactor examined, as it is a driven reactor; the increase in $\varepsilon$ reduces the heating (and, therefore, recirculated) power requirement, in addition to reducing the size of the machine.

Consider the PCA: $\mathrm{H}_{2} \mathrm{O}:{ }^{3} \mathrm{He}=30: 60: 10$ blanket of Table 6; its effective $\epsilon_{\mathrm{D}-\mathrm{T}} 1 \mathrm{~s} 1.476$ (set to preserve the total blanket energy multiplication when $\varepsilon_{D-D}$ is taken to be 1.76 , as in the TCD reactor studies - see Table 7). Using the sensitivity data of Table 12 it is estimated that the difference between the 1.476 and the $\varepsilon_{\mathrm{D}-\mathrm{T}}=1.50$ taken for the $\mathrm{TCD}$ reactor studies (see Table 7) could be responsible for a mere one-third of a percent increase in the TCD reactor $\mathrm{COE}$.

\subsubsection{Effect of First Wall Thermal Loading}

Table 13 illustrates the sensitivity of the Cat-D and D-T reactors to the first wall thermal loading $\left(\phi_{W}\right)$ constraint. The Cat-D reactor is seen to benefit the most from increasing $\phi_{W}$; 1 ts $\operatorname{COE}$ 1s reduced by $23 \%$ versus $8.5 \%$ for the D-T reactor. ${ }^{d}$ The relatively small reduction in the $D-T$ reactor COE 18 due to the relatively small size and low cost of its fuston device to begin with, as well as to the frequent first wall/blanket replacements dictated by Its high neutron wall loadings.

\footnotetext{
dit appears that the version of TRAC-II used for the present study is not set to properly account for the effect of varying wall loading on the scheduled component replacement cost, and therefore on the COE.
} 
TABLE 13

Effect of First Wall Thermal Loading $\left(\phi_{w}\right)$ Constraint on Selected Characteristics of the D-T and Cat-D Reactors

\begin{tabular}{|c|c|c|c|c|}
\hline \multirow[b]{2}{*}{ Charcteristic } & \multicolumn{4}{|c|}{ Reactor } \\
\hline & \multicolumn{2}{|c|}{$\mathrm{D}-\mathrm{T}$} & \multicolumn{2}{|c|}{ Cat-D } \\
\hline$\phi_{\mathrm{W}}\left(\mathrm{MH} / \mathrm{m}^{2}\right)$ & $1.0^{a}$ & 2.0 & $1.0^{\mathrm{a}}$ & 2.0 \\
\hline$n_{D}\left(10^{20} \mathrm{~m}^{-3}\right)$ & 1.2 & 2.1 & 2.0 & 3.4 \\
\hline$R(m)$ & 6.1 & 4.2 & 10.6 & 7.4 \\
\hline$B_{\max }(T)$ & 8.3 & 13.2 & 13.3 & $18.8^{b}$ \\
\hline $\begin{array}{l}\text { Total neutron wall } \\
\text { loading }\left(\mathrm{MW} / \mathrm{m}^{2}\right)\end{array}$ & 4.0 & 8.0 & 0.58 & 1.15 \\
\hline Total capital cost (B\$) & 1.97 & 1.65 & 3.83 & 2.92 \\
\hline $\operatorname{COE}(\mathrm{mills} / \mathrm{kWh})$ & 27.2 & 24.9 & 47.2 & 36.8 \\
\hline
\end{tabular}

${ }^{a}$ Corresponding to the reference reactor (Ref. 23).

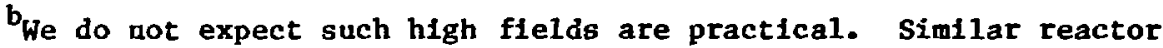
characteristics will be attained with, say, 14.3 Tesla $B_{\text {max }}$ if $B$, and correspondingly $\mathrm{n}_{\mathrm{D}}$, could be tncreased by $(18.8 / 14.3)^{2}=1.73$.

\section{POTEFTIAL FOR IPPROVBMRNTS}

\subsection{Increased Blanket Energy Hultiplication}

The Cat-D and TCD reactors considered in this work use (after Refs. 4 and 23) PCA steel for the primary neutron absorbing material. This reflects the realization $[4,11,31]$ that steel offers a high bianket energy multiplication while enabling a relatively simple blanket design. Materials having higher binding energy release per neutron capture (to be denoted by $Q_{n}$ ), Including chromiun, silicon, nitrogen [31], aluminum [11], and sodium [36] have been considered also, but found not to provide higher energy multiplication than steel. The inclusion of a beryllium neutron multiplier in the blanket was found $[11,31,36]$ to increase the blanket energy multiplication, but only modestly.

It was recently recognlzed [37] that manganese can provide a relatively high blanket energy multiplication - due to the extra binding energy release In the $\beta$ decay of the manganese $(n, \gamma)$ transmutation product, 


$$
{ }^{55} \mathrm{Mn}(\mathrm{n}, \gamma){ }^{56 \mathrm{Mn}}\left[\mathrm{Q}_{Y}=7.27 \mathrm{MeV}\right] \frac{\mathrm{B}}{2.58 \mathrm{~h}}{ }^{56} \mathrm{Fe}\left[Q_{\mathrm{r}}=3.71 \mathrm{MeV}\right]
$$

in which $Q_{r}$ is that part of the binding energy released in the $\beta$ decay which is recoverable. Even higher binding energy release is associated with a neutron capture in sodium and aluminum,

$$
{ }^{23} \mathrm{Na}(\mathrm{n}, \gamma){ }^{24} \mathrm{Na}[\mathrm{Q}=6.97 \mathrm{MeV}] \underset{15 \mathrm{~h}}{\stackrel{B}{\longrightarrow}}{ }^{24} \mathrm{Mg}\left[Q_{\mathrm{r}}=4.68 \mathrm{MeV}\right]
$$

and

$$
{ }^{27} \mathrm{Al}(\mathrm{n}, \gamma){ }^{28} \mathrm{Al}[\mathrm{Q}=7.73 \mathrm{MeV}] \underset{2.2 \mathrm{~m}}{\stackrel{\beta}{\longrightarrow}}{ }^{28} \mathrm{Si}\left[Q_{r}=3.02 \mathrm{MeV}\right] .
$$

However, the mean-free path for neutron capture in sodiun and aluminum is extremely long -- of the order of $100 \mathrm{~cm}$ for thermal neutrons. In contrast, the mean-free path for thermal neutron capture in manganese is a few centimeters only.

Substituting manganese for thorium in the hellum-cooled beryllium containing (in the form of pebbles) flssion-suppressed blanket recently designed [38] for fusion breeder applications, energy multiplication of 2.02 and 4.79 are obtained [39] for, respectively, D-T and D-D neutrons. Relative to the $\varepsilon_{D-T}=1.50$ and $\varepsilon_{D-D}=4.56$ of the reference Cat-D blanket (calculated with the same data set and calculational tools used for the study of high energy multiplication blankets), the beryllium-manganese blanket offers, respectively, 35\% and 5\% higher energy multiplication. Even higher energy multiplication is likely to be attainable by optimizing the beryllium-manganese blanket.

Table 14 compares selected characteristics of the TCD reactors of Table 10 with those of the corresponding reactors which use the beryllium-manganese blanket. The energy multiplication of this blanket are deduced from those calculated for a Cat-D reactor [39] by subtracting (9.79-0.76) $=9.03 \mathrm{MeV}$ for each neutron capture in ${ }^{3} \mathrm{He}$. The number of ${ }^{3} \mathrm{He}$ atoms converted into tritons per $D-T\left(Y_{D-T}\right)$ and per $D-D\left(Y_{D-D}\right)$ neutron are assumed to be those calculated for the $\mathrm{PCA}: \mathrm{H}_{2} \mathrm{O}:{ }^{3} \mathrm{He}$ blankets (see Sec. 2.5). In reality we expect a different split between $Y_{D-T}$ and $Y_{D-D}$ for the beryllium-manganese blanket. 
TABLE 14

Effect of a Bery11lum-Manganese Blanket on Selected Characteristics of TCD Reactors*

\begin{tabular}{|c|c|c|c|c|}
\hline \multirow[b]{2}{*}{ Characteristic } & \multicolumn{2}{|c|}{ Case A } & \multicolumn{2}{|c|}{ Case B } \\
\hline & $\mathrm{PCA}: \mathrm{H}_{2} \mathrm{O}$ & Be:Mn & $\mathrm{PCA}: \mathrm{H}_{2} \mathrm{O}$ & Be: $\because \cdots 1$ \\
\hline$\alpha$ & \multicolumn{2}{|c|}{0.90} & \multicolumn{2}{|c|}{0.765} \\
\hline No. $D-T$ per $D-D$ neutrons & \multicolumn{2}{|c|}{1.80} & \multicolumn{2}{|c|}{1.64} \\
\hline$Y_{D-T}$ & \multicolumn{2}{|c|}{0.335} & \multicolumn{2}{|c|}{0.295} \\
\hline$D-D$ & \multicolumn{2}{|c|}{0.465} & \multicolumn{2}{|c|}{0.420} \\
\hline $\bar{\varepsilon}_{D-T}$ & 1.320 & 1.834 & 1.339 & 1.858 \\
\hline $\bar{\varepsilon}_{D-D}$ & 2.894 & 3.272 & 3.064 & 3.475 \\
\hline $\bar{\varepsilon}$ & 1.459 & 1.960 & 1.505 & 2.013 \\
\hline Relative Increase in $\bar{\varepsilon}(\%)$ & \multicolumn{2}{|c|}{34.4} & \multicolumn{2}{|c|}{33.0} \\
\hline Reduction in COE (\%) & \multicolumn{2}{|c|}{8.3} & \multicolumn{2}{|c|}{8.1} \\
\hline Estimated COE (mills $/ \mathrm{kWh})$ & \multicolumn{2}{|c|}{32.1} & \multicolumn{2}{|c|}{33.6} \\
\hline
\end{tabular}

* Corresponding to the reactors of Table 10 .

This difference is not expected to affect, nevertneless, the average blanket energy multiplication. The $-34 \%$ increase in this average energy due to beryllium and manganese is estimated (using the information of Table 12) to lead to a $-8 \%$ reduction in the $\mathrm{COE}$.

\subsection{Lon Cost Shield}

It was recently proposed [40] that by using concrete and water as the primary outboard and penetration shield coustituents, it might be possible to reduce the capital cost of a STARFIRE-1ike tokamak by $-8 \%$. A similar effect is expected in Cat-D and TCD tokamaks. The corresponding savings in the $\mathrm{COE}$ of these fuston power reactors is estimated to be $7 \%$. As the total shleld cost for the $D-D$ based reactors is higher than that for the D-T reactor, the saving In the shield cost will decrease the absolute difference between the COE of the D-T and TCD (as well a.s Cat-D) reactors.

It is likely that additional cost saving could be arrived at by minimizIng the thickness (and cost) of the Inboard blanket and shield [41-43]. Such 
a thickness reduction might be even more significant for reducing the maximal toroidal magnetic field strength requirement (for providing a given fleld in the plasma) for the TCD mode of operation.

\subsection{High bergy Conversion Efficteng}

Not required to breed at least one triton per fusion neutrou (and, thus, having more freedon in material choices, first wall thickness, etc.), and not having to contain lithium in its blanket (and, thus, being free from the upper temperature constraint 1mposed by solid breeding materials, and having more freedom in material choice), blankets for TCD (and Cat-D, etc.) reactors might be designed to have a higher thermal efflctency than that of a $D-T$ reactor. Assuming that a hellum-cooled blanket could be designed to have a thermal efficlency of $42 \%$ (after Ref. 44), it is estimated that the COE of the TCD ractors of Table 10 can be lowered by $-16 \%$.

Even higher nuclear-to-electrical energy conversion efficlencies might be realizable if the blanket is desigued as a "high temperature" blanket [44-46]. With their relaxed tritium production requirements and relatively high (compared with Cat-D reactors) fraction of fusion energy in the form of neutron kinetic energy, the TCD mode of operation appears to be more sultable than either the D-T or Cat-D modes of operation for driving such high temperature blanket systens $[2,47]$.

\subsection{Discussion}

Table 15 summarizes the reductions in the COE which might be obtained by the possible design improvements described in secs. 4.1 to 4.3 . It is observed that if all three improvements are realizable, the COE estimated for the TCD reactors may be comparable to that of the reference D-T tokamak, and lower than that of the Cat-D tokanak.

\section{5. conchudug rahites}

The preliminary assessment of the promise of the tritium catalyzed deuterlum mode of operation for tokamak power reactors carried out 1n this work in-

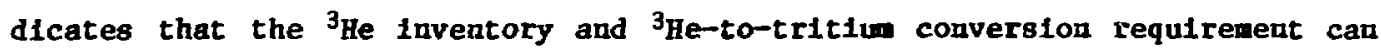
probably be met without much difficulties. In fact, it 1s very 11kely that, 
TABLE 15

Summary of Potential Improvements in the Cost of Electricity (COE) of TCD Versus D-T and Cat-D Reactors

\begin{tabular}{|c|c|c|c|c|}
\hline \multirow[b]{3}{*}{ Scenario } & \multicolumn{4}{|c|}{ Cost of Electricity (m111s/kWh) } \\
\hline & \multirow[b]{2}{*}{$D-T^{2}$} & \multirow[b]{2}{*}{ Cat $-D^{a}$} & \multicolumn{2}{|c|}{$\operatorname{TCD}^{b}$} \\
\hline & & & Case A & Case B \\
\hline Reference & 27.1 & 46.2 & 35.0 & 36.6 \\
\hline (1) Beryl11um-manganese blanket & $-\infty$ & 42.4 & 32.1 & 33.6 \\
\hline (2) Low cost shield & 25.2 & 43.0 & 32.6 & 34.0 \\
\hline (3) High efficlency & --- & 38.8 & 29.4 & 30.7 \\
\hline Combined $[(1)+(2)+(3)]$ & 25.2 & 33.1 & 25.1 & 26.2 \\
\hline
\end{tabular}

${ }^{\text {From Table } 9 .}$

brom Tab1e 10.

as a result of blanket optimization studies, the ${ }^{3}$ He Inventory could even be significantly lower than estimated in this work.

The TCD mode of operation alleviates difficulties associated with ${ }^{3}$ He recirculation to the plasma which is needed for the realization of Cat-D (and Cat-D-T) systems. These difficulties include the need for the recovery of ${ }^{3} \mathrm{He}$ from the ash, for its isotopic separation from the hellum, and for refueling the ${ }^{3} \mathrm{He}$. For Cat-D fuston these operations need be done many times per ${ }^{3} \mathrm{Be}$ atom (due to the low ${ }^{3} \mathrm{He}$ fusion probability per confinement time) and could therefore result in non-negligible ${ }^{3} \mathrm{He}$ loss and economic penalty.

Relative to D-T reacto: , TCD reactors offer the possibility for designing simpler and safer blankets. This is due to the following characteristics of TCD blankets:.

- No necessity for Incorporating lithium in the blanket. (The ${ }^{3}$ He-to-tritium converting system could be restricted to the outboard blanket, as could the relatively small amount of lithlum, if tritium assistance is called for.)

- No need for neutron multiplying materials.

- Iow (and easy to extract) tritium inventory. 
- More flexibility in materials selection and blanket design, possibly enabling the design of low activation blankets and long-life (relative to D-T reactor) first wall system.

The environmental and economic implications of these potential merits need to be evaluated in detall [along with potential difficulties of TCD blankets (such as the ${ }^{3} \mathrm{He}$ retention) and TCD plasmas (see in the following)] for the prospects of TCD reactors to be reliably assessed.

A number of lssues associated with the ${ }^{3}$ He-to-tritium conversion system for TCD reactors were not addressed in this work. These Include: the confinement of ${ }^{3} \mathrm{He}$ in the blanket system; ${ }^{3} \mathrm{He}$ makeup; tritium inventory in the blanket (and in the entire reactor); and out-of-blanket ${ }^{3}$ He inventory. A detalled study of these issues need be undertaken before the practical realization of the TCD mode of operation could be reliably established. Concerning the ${ }^{3}$ He makeup issue it ought to be realized that there is no need for maintaining the ${ }^{3} \mathrm{He}$ in a highly pure Isotoplc state (as is required for fueling Cat $-D$ reactors); all that is necessary for the TCD system is to maintain the desired ${ }^{3} \mathrm{He}$ I nventory in the blanket. Nevertheless, due to the consumption of ${ }^{3} \mathrm{He}$, it may be necessary to extract ${ }^{4} \mathrm{He}$ (assumed to be fed in along with the ${ }^{3} \mathrm{He}$ ) from the helium systen.

The TCD mode of operation appears to be compatible with the design of blankets for high energy multiplication as well as for high temperature operation. Such blankets are 11kely to significantly improve the economic viabi1Ity of TCD (as well as of other D-D based) reactors. It is highly recommended that the feasibility of realistic designs of high multiplication and high temperature TCD blankets be thoroughly explored.

As far as the plasma properties are concerned, TCD plasmas are characterized by a significantly higher power density than Cat-D (and even Cat-D-T) plasmas. Being neutron rich (i.e., having significantly higher neutron power density than Cat-D plasma), TCD reactors can benefit more than Cat-D reactors from high energy multiplication blankets. However, as far as the plasma 1gnition and confinement requirements are concerned, the TCD is more demanding than the Cat-D mode of operation.

Even though TCD plasmas are lean in ${ }^{3} \mathrm{He}$ and, thus, subjected to lower radiation energy losses, the fraction of fusion energy deposited in these 
plasmas may not be sufficient to allow ignition unless part of the ${ }^{3} \mathrm{He}$ is recirculated (so as to increase the fraction of the ${ }^{3}$ He which'fuses). Alternatively, Ignition could be arrived at by assisting the TCD plasma with tritIum bred in the blanket from 1ithium (in addition to the ${ }^{3}$ He bred tritium). of the two schemes, tritium assistance is likely to be the more economical, as it increases the relative contribution of the blanket to the reactor power output, and enables maintaining the plasma with a lower helium concentration (and hence, lower radiation losses). Electrical heating could also maintain the TCD plasma energy balance, but is less desirable economically.

The smaller the ion to energy confinement time ratio, the better are the TCD plasma chances for ignition. The ratio assumed for the present analysis (after Ref. 23) is $\tau_{p} / \tau_{E}=4$. Had $1 t$ been possible to preferentlally accelerate the leakage of the hellum lons without unduly impairing the plasma energy confinement time, the better becomes the chances of TCD plasmas to ignite.

Even if having favorable enough energy balance to allow ignition, the high $\beta B_{\mathrm{T}_{\text {max }}}^{2}$ requirements for confining TCD plasmas to operate at the proper power density may not be attainable in a tokamak system, unless the $\beta \sim 15 \%$ regime is accessible. Magnetic field configurations capable of high plasma confinement might be more suitable than tokamaks for the TCD mode of operation. Of the high $B$ alternatives, the compact reversed field pinch (CRFP) scheme [48] appears quite promising. Thus, a thorough feasibility study of TCD CRFPRs is highly recommended.

The assessment of the promise of the TCD mode of operation cannot be complete without considering also nonelectrical applications of 'fusion energy, notably fissile and synthetic fuel production. A preliminary assessment of the promise of TCD tokamaks for fissile fuel production has been done already [5,26]. It appears, though, that being more compact and efficient (1n terms of recirculating power fraction requirements), the TCD tokamak designs of the present work are 11 kely to offer more economical fuston breeders. The synthetic fuel production ability of TCD tokamaks deserve studying, possibly in connection with the study of the feasibility and implications of high temperature blankets.

Particularly promising for synfuel production is the Iritium-assisted Semi-Catalyzed Deuterium (SCD-T) mode of operation in which the ${ }^{3}$ He extracied 
from the plasma is not converted into tritium; instead, a comparable amount of tritiun is produced in the blanket from lithium). In addition to synthetic fuel, the SCD-T reactor is to produce ${ }^{3} \mathrm{He}$. This ${ }^{3} \mathrm{He}$ is to be used as the fuel (the other fuel, deuterium, is abundant enough) for the relatively clean $D-{ }^{3} \mathrm{He}$ fusion power reactors [25]. Whereas the SCD-T fuel factorles could be located away from population centers, the much "cleaner" (of neutrons, tritiun and 11thfun) D-3 He electricity-generating reactors could be located close to population centers.

In fact, the SCD- $T$ mode of operation might be a natural following of $D-T$ fusion, even if the latter is successfully developed and accepted by the pub11c. This can happen when the economically recoverable resources of $6 \mathrm{Lt}$ are depleted. By that time huge inventories of ${ }^{7} \mathrm{LS}$ (or depleted 11thium) will be accumulated. This ${ }^{7} \mathrm{Li}$ could provide ample tritium for SCD-T (as well as Cat-D reactors.

In conclusion, we feel that the promise of the partially catalyzed deuterium fusion fuel cycles, including the TCD (as well as the TCD-T) and the SCD-T modes of operation is significant enough to warrant furi.jer consideration. It is recommended that comprehensive and systenatic TCD (and the like) reactor design studies be undertaken (as our knowledge of the scientific and technology bases for fusion improves) along with the study of generic issues such as the feastbility of a long-life first wall, of high energy mutiplication and high temperature blankets, etc.

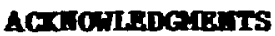

Helpful discussions with Dr. Kenneth Evans, Jr. concerning the TRAr-rI program, and with Dr. Patricia Finn concerning the separation and retent io. $7 \frac{1}{4}$ ${ }^{3}$ He and tritium are gratefully acknowledged. The authors would also like to acnowledge the substantial efforts of Cyrilla Hytry and Chris Stalker for the preparation of the manuccipt. 


\section{REFERWGS}

1. E. Greenspan and G. H. Miley, "Tritiun-Catalyzed Deuterium (TCD) Fuston Reactors," Proc. IEEE Intern. Conf. on P1asna Science (1981), p. 59.

2. E. Greenspan and G. H. Miley, "Partially-Catalyzed-Deuterium and TritiumAssisted Plasma Characteristics," Nuc1. Technol./Fusion 4 , 590 (1982).

3. S. E. Attenberger and W. A. Houlberg, "Plasma Physics Sensitivity Analysis of Catalyzed-D Operation in Tokamaks," Proc. 4th Top. Mtg. on Technology of Controlled Nuclear Fusion, CONF-801011 (1981), p. 941.

4. K. Evans, Jr., et al., WILDCAT: A Cataiyzed D-D Tokamak Reactor," Argonne Nat1onal Laboratory, ANL/FPP/TM-150 (1981).

5. E. Greenspan and G. H. Miley, "Tritium-Assisted Fusion Breeders," Lawrence Livermore National Laboratory Report, UCID-19874 (1983).

6. R. G. Milis, "Catalyzed Deuteriun Fusion Reactors," Princeton Plasma Physics Laboratory, TM-259 (1971).

7. G. H. Miley, F. H. Southworth, C. K. Choi, and G. A. Gerdin, "Catalyzed-D and $D-{ }^{3}$ He Fusion Reactor Systems," Proc. 2nd Top. Mtg. on the Technology of Controlled Nuclear Fusion, Richland, WA (1976).

8. C. K. Choi, Ed., "Proc. of the Review Meeting on Advanced Fuel Fusion," Electric Power Research Institute, EPRI-ER-536-SR (1977).

9. J. R. Powe11, T. L. Usher, and J. A. F1110, "Advanced-Fuel Tokanak Summary with Costing and Net Energy Analyses," Eiectric Power Research Inst1tute Report EPRI-ER-919 (1978).

10. R. L. Hagenson and R. A. Krakowsk1, "An Advanced-Fuel Reversed-F1eld Pinch Fusion Reactor (DD/RFPR): Prelininary Considerations," LOB Alamos National Laboratory, LA-9139-MS (1982); also LA-9389-MS (1982).

11. R. W. Conn, et al., "SATYR, A D-D Fueled Tandem Mirror Reactor Study," University of Califoruia at Los Angeles, PPG-576 (1981).

12. D. C. Baxter, et al., "D-D Tokamak Reactor Assessnent," Science Applications, Inc., SAI-25082-213LJ (1983).

13. Y. I. Kolesnichenko and S. N. Reznik, "The D-D Nuclear Fusion Reaction in a Hybrid Reactor," Nucl. Fusion 16, 97 (1976).

14. E. Greenspan, "On the Feasibility of Beam Driven Senf-Catalyzed Deuterium Fusion Neutron Sources for Hybrid Reactor Application," Princeton Plasma Physics Laboratory, PPPL-1399 (1977). 
15. D. L. Jassby, et al., "The Energetics of Seni-Catalyzed-Deuterium, LightWater-Moderated, Fusion-Fission Toroidal Reactors," Proc. 3 rd ANS Top. Mtg. or the Technology of Controlled Nuclear Fusion, CoNF-780508-P1 (1978), p. 170; also PPPL-1456 (1978).

16. D. L. Owens and A. J. Impink, "Preliminary Evaluation of the Benef1ts to - De Obtained by Introducing a ${ }^{3} \mathrm{He}-{ }^{4} \mathrm{He}$ Reglon Into the Blanket of a D-D Fusion Machine," Proc. Symp. on the Technology of Controlled Thermonuclear Fusion Experiments and the Engineering Aspects of Fusion Reactors, Univ. of Texas, Austin (1972), AEC Symp. Ser. 31, Conf-721111 (1974), p. 766 .

17. R. F. Post, "D-T Mirror Reactor Fuel Cycle Not Requiring a Lithium Blanket," Lawrence Livermore National Laboratory, UCID-16231 (1973).

18. E. Greenspan and G. H. Miley, "D-T Assisted Cat-D SAFFIRES," Proc. IEEE Intern. Conf. on Plasma Sclence, Madison, WI (1980).

19. E. Greenspan, T. Blue, and G. H. Miley, "Cat-D-T Tokamaks," Proc. 4th Top. Mtg. on the Technology of Nuclear Fusion, CoNF-801011 (1981), p. 946.

20. D. R. Cohn, et al., "Near-Term Tokamak Reactor Designs with High Performance Resistive Magnets," Proc. 3rd Technical Committee Meeting and Workshop on Fusion Reactor Design and Technology, Tokyo, Japan (1981); also, L. Bromberg, et al., "Tokamaks with High Performance Resistive Magnets: Advanced Test Reactors and Prospects for Commercial Application," Proc. 9th Symp. on Engineering Problems of Fusion Research, IZEE Pub. No. 81CH1715-2, Vol. II (1981), p. 1980 .

21. L. Bromberg, et al., "High Fleld Tokamaks with DD-DT Operation and Reduced Tritium Breeding Requirements," Proc. 5th Top. Mtg. on the Technology of Fusion Energy, Knoxville, TN (1983); also, E. Bobrov, et al., "High Field Tokamaks with DD-DT Operation and Reduced Tritium Breeding Requirements," MIT Plasma Fusion Center, PFC/RR-83-5 (1983).

22. D. Dobrott, "Alternate Fuels 1n Fusion Reactors," Proc. 5th Top. Mtg. on the Technology of Fusion Energy, Knoxville, TN (1983); Nucl. Technol./ Fusion $4(2), 333$ (1983).

23. K. Evans, Jr., J. G111igan, and J. Jung, "Tokanak Fusion Reactors with Less than Full Tritium Breeding," Argonne National Laboratory, ANL/FPP/TM-169 (1983); also, Nucl. Techno1./Fusion 5, 311 (1984).

24. J. G. G1lifgan, K. Evans, Jr., and J. Jung, "The Effective Cost of Tritium for Tokamak Fusion Power Reactors with Reduced Tritium Production Systems," Proc. 5th Top. Mtg. on the Technology of Fusion Energy, Knoxville, TN (1983); Nucl. Technol./Fusion 4(2), 273 (1983).

25. E. Greenspan and G. H. Miley, "Pathways for Fusion Penetration into the Energy Economy," University of Illinols Fusion Studfes Laboratory, FSL-32 (1980). 
26. E. Greenspan and G. H. Mlley, "Trit1um-Assisted Deuter1un-Based Fusion Breeders," Proc. 5th Top. Mtg. on the Technology of Fusion Energy, Knoxville, TN (1983); Nucl. Technol./Fusion 44(2) 167 (1983).

27. c. C. Baker, et al., "STARFIRE - A Commercial Tokamak Fusion Power Plant Study," Argonne National Laboratory, ANL/FPP-80-1 (1980).

28. "ANISN-ORNL: Multigroup One-Dimensional Discrete ordinates Transport Code with Anisotropic Scattering," 0RNL/RSIC-254, Oak Ridge National Laboratory (1973).

29. R. W. Roussin, et al., "VITAMrN-C: The CTR Processed Multigroup Cross Section Library for Neutronics Studies," Oak Ridge National Laboratory, ORNL/RSIC-37 (1980).

30. Y. Gohar and M. Abdou, "MACKLIB-IV: A Library of Nuclear Response Functions Generated with the MACK-IV Computer Program from ENDF/B-IV,Argonne National Laboratory, ANL/FPP/TM-106 (1980).

31. K. E. Evans, Jr., et al., "D-D Tokamak Reactor Studies," Argonne Natłonal Laboratory, ANL/FPP/TK-138 (1980).

32. J. R. McNally, Jr., "Physics of Fusion Fuel Cycles," Nuc1. Technol./ Fusion 2, 9 (1982).

33. P. Finn, Argonne National Laboratory, Personal Communication (August 1983).

34. P. H. Rutherford, "Physics Basis for an Ignited Long-Pu?se Tokamak," Nuc1. Technol./Fusion 4,36 (1983).

35. E. Greenspan and G. H. Mlley, "Deutertum-Based Plasmas as a Source for Helium-3," Nuc1. Technol./Fusion 2, 43 (1982).

36. H. Nakashima, et al., "Nuclear Characteristics of D-D Fusion Reactor Blarket (II) - Thermal Blanket and Blanket Shield Designs, - J. Nucl. ScI. Technol. 15, 190 (1978).

37. E. Greenspan and Y. Karni, "High Energy-Multiplication Blanket Concepts for D-D Fusion Reactors," Trans. Israeli Nuc1. Soc., 11, 197 (1983).

38. R. W. Moir, et al., "Fusion Breeder Reactor Design Studies, "Nuc1. Technol./Fusion 4(2), Pt. 2, 589 (1983); also, UCID-19638 and UCRL-88872 (1983).

39. E. Greenspan and Y. Karni, "High Bnergy Multiplication Blankets for Cat-D Fusion Reactors," Trans. Am. Nuc1. Soc. 46,217 (1984).

40. Y. Gohar, "Low Cost Shield for Tokamak Fusion Reactors," Nucl. Technol./ Fusion 4 (2), Pt. 2, 373 (1983).

41. D. Gilai, E. Greenspan, and P. Levin, "On Optimal Shields for Fuston Reactors," Proc. 6th Intern. Conf, on Radiation Shielding, Tokyo, Japan (1983). 
42. D. Gilai, E. Greenspan, and P. Levin, "Optimal W-TiH 2 Shields for Fusion Reactors," Trans. Am. Nuc1. Soc. 45, 625 (1983).

43. P. Levin, E. Greenspan, and D. Gilai, "Effect of Neutron Source Spectrum on Optimal Shield Composition and Performance," Trans. Israeli Nuc1. Soc. $\underline{11}, 263$ (1983).

44. A. Herzberg and $J$. R. Powe11, "Report of Power Cycle Group," Proc. BNL Fusion/Synfuel Workshop, Brookhaven National Laboratory, BNL-51188 (1979).

45. J. Powell, J. Fillo, and H. Makowitz, "The FAST Power Cycle for Fusion Reactors," Proc. 13th IECEC, San Dlego, CA, Vo1. 2, (Society of Automotive Engineers, Inc., 1978), p. 1377.

46. A. Herzberg, "The Impact of High Efficiency Energy Conversion on Fusion Systems," Proc. IEEE Intern. Conf. on Plasma Science, CONF-810508 (1981), p. 99.

47. R. Bourque, "Appendix B. Power Conversion Systems," in M. Abdou, et al., "Blanket Comparison and Selection Study," Argonne National Laboratory, ANL/FPP-83-1, Vo1. II (1983), P. B-1.

48. R. L. Hagenson and R. A. Krakowski, "Compact Reversed-Field Pinch Reactors (CRFPR): Sensitivity Study and Design-Point Determination," Los Alamos National Laboratory, LA-7389-MS (1982). 
Detribution for ATW/FPR/mi-183

Interna1: :

\begin{tabular}{lll}
\hline & S. KIn & D. Salth \\
C. Baker & R. Kustom & D. Sze \\
J. Brooks & L. LeSage & L. Turner \\
Y. Cha & Y. Liu & ANL Patent Dept. \\
R. Clemmer & S. Majumdar & FP Program (15) \\
D. Ehst & V. Maroni & ANL Contract File \\
K. Evans & R. Mattas & ANL Libraries (2) \\
R. Finn & B. Misra & TIS FIles (6) \\
Y. Gohar & J. Norem & \\
A. Hassanein & R. Nygren & \\
C. Johnson & W. Praeg & \\
J. Jung (5) & J. Roberts &
\end{tabular}

External:

DOE-TIC, for distribution per UC-20, -20b, -20d (155)

Manager, Chicago Operations office, DOE

Special Committee for the Fusion Program:

S. Baron, Burns \& Roe, Inc., Orade11, NJ

H. K. Forsen, Bechtel Group, Inc., San Franc1sco

J. Maniscalco, TRW, Inc., Redondo Beach

G. H. Miley, University of Illinots, Urbana

P. J. Reardon, Brookhaven National Laboratory

P. H. Rutherford, Princeton P1asma Physics Laboratory

D. Steiner, Rensselaer Polytechnic Institute

K. R. Symon, University of Wisconsin-Madison

K. Thomassen, Lawrence Livermore National Laboratory

M. Abdou, University of California-Los Angeles

R. Bourque, GA Technologies, Inc.

E. Cheng, GA Technologies, Inc.

R. Conn, University of California-Los Angeles

D. R. Cohn, Massachusetts Institute of Technology

B. Coppi, Massachusetts Institute of Technology

J. Giligan, North Carolina State University (5)

E. Greenspan, Nuclear Research Center-Negev, Israel (5)

R. Hagenson, Technology International

C. Henning, Lawrence Livermore National Laboratory

R. A. Krakowsk1, Los Alamos National Laboratory

L. S. Masson, EG\&G Idaho, Inc.

D. L. Jassby, Princeton Plasma Physfcs Laboratory

T. Kammash, University of Michigan-Ann Arbor

G. B. Logan, Lawrence Livermore National Leboratory

G. H. Miley, University of Illinols (5)

R. Molr, Lawrence Livermore National Laboratory

H. Nakashima, Kyushu Unfversity, Fukuoka, Japan

R. Nebel, Ios Alamos National Laboratory

M. Peng, Oak RIdge National Laboratory

D. Post, Princeton Plasma Physics Laboratory

M. Ragheb, University of Illinois

K. A. Schultz, GA Technologies, Inc. 
M. Sawan, University of Wisconsin-Madison

Y. Sek1, Tokal Research Establishment, JAERI, Japan

W. M. Stacey, Jr., Georgla Institute of Technology

L. Steinhauer, Mathematical Sclences Northwest

A. M. M. Todd, Grumman Aerospace Corporation

S. E. Walker, Ph1ll1ps Petroleun Company

H. Wodson, University of Texas-Austin 